\title{
On the linguistic complexity of proper names
}

\author{
Ora Matushansky
}

Published online: 4 February 2009

(C) The Authors(s) 2009. This article is published with open access at Springerlink.com

\begin{abstract}
While proper names in argument positions have received a lot of attention, this cannot be said about proper names in the naming construction, as in "Call me Al". I argue that in a number of more or less familiar languages the syntax of naming constructions is such that proper names there have to be analyzed as predicates, whose content mentions the name itself (cf. "quotation theories"). If proper names can enter syntax as predicates, then in argument positions they should have a complex structure, consisting of a determiner and its restriction, like common nouns (cf. "definite description theories of proper names"). Further consideration of the compositional semantics of proper names in the naming construction also shows that they have another argument slot, that of the naming convention. As a result, we will be able to account for the indexicality of proper names in argument positions and provide compositional semantics of complex and modified proper names (e.g., the famous detective Sherlock Holmes).
\end{abstract}

Keywords Proper names - Description theories - Quotation theories · Naming construction $\cdot$ Small clauses $\cdot$ ECM verbs $\cdot$ Change-of-state

\section{Introduction}

Much work has been done on the semantics of proper names, while their syntax has not received enough attention. Most semantic analyses view proper names as

O. Matushansky $(\bowtie)$

UiL OTS/Utrecht University, Utrecht, The Netherlands

e-mail: Ora.Matushansky@let.uu.nl; matushan@univ-paris8.fr

homepage: http://www.let.uu.nl/ ora.matushansky/personal/

O. Matushansky

CNRS/Université Paris-8, Saint Denis Cedex, France 
syntactically simplex, with no internal structure whatsoever. This approach is compatible with viewing proper names as directly referring rigid designators (starting with Kripke 1980), indexicals (Recanati 1997; Pelczar and Rainsbury 1998) or definite descriptions (Frege 1983; Russell 1911; Searle 1958; Kneale 1962; Burge 1973; Katz 1977, 1990, 1994; Kleiber 1981; Bach 1981, 1987, 2002; Liu 2004, etc.). However, the definite description approach is also compatible with proper names being both semantically and syntactically complex (see Geurts 1997; Elbourne 2002), in which case they can be viewed as syntactically decomposable into a definite article (or a demonstrative, as in Larson and Segal 1995) and a predicate.

While proper names in argument positions have received a lot of attention, especially in philosophy of language, this cannot be said about proper names used in the naming construction, exemplified in examples like (1), which are generally assumed to involve "mention" rather than "use" of proper names, or possibly to be completely meta-linguistic.

(1) a. Call me Al.

naming construction

b. In the end of the 20th century the city was renamed St. Petersburg.

c. The St. Olga of the Orthodox church was actually baptized Helen.

In this paper I show that naming verbs are essential for our understanding of the syntax and semantics of proper names. The syntax of naming constructions is such that proper names there have to be analyzed as predicates, whose contents mentions the name itself. This lends support to the so-called "quotation theories" of proper names in argument positions (Kneale 1962; Kleiber 1981; Bach 1981, 1987, 2002; Geurts 1997; Elbourne 2002, etc.).

The assumption that proper names can enter syntax as predicates reasonably entails that they have a complex internal structure in argument positions, consisting of (at least) a determiner and its restriction, exactly like noun phrases whose heads are common nouns. Nonetheless, further consideration of the interpretation of proper names in the naming construction also shows that they have another argument slot, that of the naming convention. As a result, we will be able to provide a compositional account of the naming construction, as well as to provide a semantic account of proper names in argument positions that will compositionally derive the fact that they generally behave rigidly (Kripke 1980; Recanati 1997; Pelczar and Rainsbury 1998, etc.).

The paper is arranged as follows. First I will consider cross-linguistic syntax of the naming construction. Although the first impression given by verbs of naming is
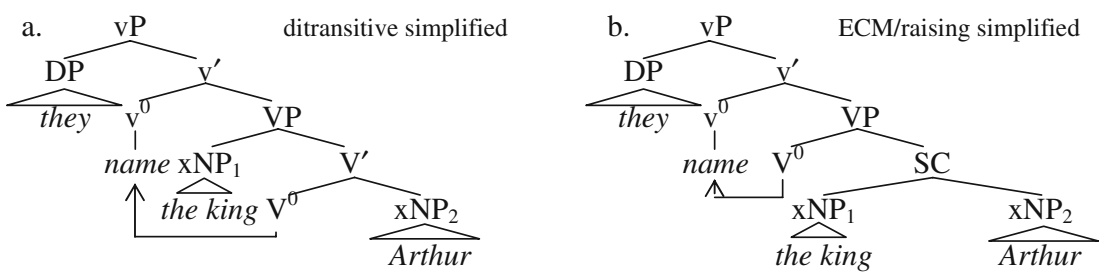
that they are ditransitive, as in (2a), Sect. 2 will show that this impression is false and they project a small clause structure, as in (2b).

If the second extended NP $\left(\mathrm{xNP}_{2}\right)$ in naming constructions is a predicate, proper names can (though perhaps do not have to) enter syntax as predicates. ${ }^{1}$ This removes one of the standardly presupposed differences between common nouns (assumed to start out as predicates) and proper names, and thus permits us to view proper names as definite descriptions when they appear in argument positions (unless some other determiner is present).

Section 3 will introduce certain assumptions about the semantics of proper names that must be made if we are to explain their behavior in naming constructions. Section 4 will show that these assumptions account for their properties in argument positions and compositionally derive the indexicality of the proper names (rigidity, according to Kripke 1980). It will also discuss some further predictions made by this approach, in particular regarding the semantics of complex and modified proper names (e.g., the famous detective Sherlock Holmes). Section 5 returns the discussion to proper names in naming constructions; it will be argued that no special proviso is required for the semantic treatment of those. Section 6 is the conclusion and a discussion of new venues for future research.

In general, the approach advocated here rests fully on the assumptions already made about proper names in the semantic and philosophical literature. Following Geurts (1997), Recanati (1997) and Pelczar and Rainsbury (1998), I will argue that proper names are underlyingly predicates, and I will rely on the cross-linguistic syntax of the naming construction to provide an independent motivation for this assumption. In order to compositionally account for the interpretation of the naming construction I will have to assume that proper names have an argument slot for a naming convention, which will later permit me to treat the indexical of the naming convention in force (Recanati 1997) as a contextually provided free variable. In other words, the novelty of this approach lies in (a) the independent motivation of the definite description view of proper names and (b) a particular syntactic and semantic realization of the hypothesis that the rigidity of proper names results from an indexical of the name-assigning convention or dubbing in force (Recanati 1997; Pelczar and Rainsbury 1998). I will show that these two factors will permit us to account for the behavior of proper names both in the naming construction and in argument positions, including cases where proper names appear with overt determiners.

Importantly, this paper does not discuss the full range of morpho-syntactic and semantic properties of proper names. In particular, it does not deal with the syntax of their well-known ability to appear without an article (Sloat 1969; Longobardi 1994, 1999 et seq., and Borer 2005, among others; see Matushansky 2006b for a proposal) or with special preproprial definite articles (e.g., in Catalan or Maori). It also does not discuss the question of how a given proper name becomes associated with a given individual and only touches briefly upon names of entities other than individuals, such as guises or stages.

\footnotetext{
${ }^{1}$ I use the term xNP rather than NP or DP where it is irrelevant which functional layers are projected.
} 


\section{Syntax of naming constructions}

Naming constructions, where a proper name is assigned to an individual, seem to be syntactically very similar to those change-of-state constructions where an individual receives a nomination (new post, new position, new status, etc.). In this section I will argue that naming constructions, illustrated in (3a), have exactly the same syntax as the change-of-state construction in (3b):

(3) a. The king of all England was named Arthur.

naming

b. Arthur was named the king of all England.

nomination

First indications in favor of this hypothesis come from the fact that the same verbs may be used in both constructions: in the list below, italics indicate naming verbs, while boldface is used to mark verbs that can function both in naming and change-of-state nomination constructions: ${ }^{2}$

(4) anoint, appoint, baptize, brand, call, choose, christen, crown, declare, designate, $d u b$, elect, make, name, nickname, nominate, proclaim, pronounce, style, title, vote

It seems rather straightforward that nomination verbs take a small clause complement (see also Stowell 1989; Levin 1993). In particular, nomination verbs can hardly be set apart from the verb make, which clearly takes a small clause.

\subsection{Small clauses}

A small clause is a minimal syntactic structure containing a subject and a non-verbal predicate (Stowell 1981, 1983). ${ }^{3}$ Its exact internal structure is irrelevant for our purposes:

(5)

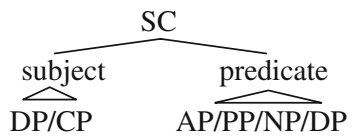

Small clauses can appear as complements to many verbs, some of them intensional, and their subjects receive case either directly (the so-called Exceptional Case Marking, or ECM) or concomitantly with being raised to the [Spec, TP] of the matrix verb:

(6) a. They made [sc Alice (the) president/head of the association].

ECM

b. Alice became [sc $t_{i}$ (the) president/head of the association]. Raising

\footnotetext{
${ }^{2}$ Most verbs in this list come from Levin (1993), who places verbs of naming and nomination into the more general category of verbs that take predicative complements. Some verbs in the list are archaic in their naming or nomination use $(d u b)$, and a few (e.g. declare) are preferred with as-small clauses. I believe the list to be complete.

3 Some researchers consider infinitival VPs to also be small clauses. Since verbs of naming only appear with nominal predicates, we are not concerned with exact categorial specification of small clauses here.
} 
The predicate of a small clause can be an XNP, an AP or a PP; its subject may be a DP or a $\mathrm{CP}$ :

(7) a. They made Alice president/a professor.

b. This proposition is/seems $\left[\mathrm{SC} \mathrm{t}_{\mathrm{i}}\right.$ preposterous/out of the question.

c. [CP That Jessie should fight] was considered [sC $\mathrm{t}_{\mathrm{i}}$ obvious].
xNP predicate

AP/PP predicate

CP subject

Small clause predicates have a range of properties cross-linguistically. In some languages nominal predicates must appear without an article; we will be particularly interested in situations where, as in (6), it is definite predicates that do so (Stowell 1991). Predicates can show particular case-marking (case agreement with the subject, or dedicated predicative case). I will show that naming constructions systematically exhibit the same cluster of syntactic behavior across various languages (Arabic, Breton, English, Finnish, French, German, (Modern) Greek, Latin, Pima, Russian, Scandinavian...) as verbs known to take small clause complements-in particular, as nomination verbs. ${ }^{4}$

\subsection{Cautionary notes}

Before we turn to cross-linguistic data, it should be observed that neither nomination verbs nor naming verbs form a fully homogeneous class with respect to every syntactic property: for both classes of verbs class-internal variation is present. For example, some nomination and naming verbs are morphologically derived (e.g., crown, appoint), whereas others are not (choose, dub). Syntactic class-internal variation also holds with respect to changes in argument structure and availability of implicit arguments: some naming and nomination verbs allow $\mathrm{xNP}_{2}$ drop (e.g. baptize, elect), while others don't (nickname, declare), and for those that do, the drop of $\mathrm{xNP}_{2}$ may or may not be accompanied by a change in meaning (baptize vs. elect). Since these facts are beyond the scope of this paper, they will not be discussed here.

Finally, the verb call is often special, in many languages, and allows many more uses than the others, including in particular the option of using it with an AP or common noun predicate:

(8) a. My friends call me charming.

b. Here's a pot calling the kettle black.

The exceptional behavior of call across languages is the reason why no conclusions will be based on its properties alone. Likewise, cases where the $\mathrm{xNP}_{1}$ or

\footnotetext{
${ }^{4}$ The structure that naming verbs project is not invariant across languages. In Hindi (Anoop Mahajan and Rajesh Bhatt, p.c.) no proper naming verbs exist, instead paraphrase is used (e.g., "give a name"). In Georgian (Lea Nash, p.c.), the naming construction is clearly ditransitive, one of the two relevant verbs is bi-morphemic and means "give a name" (incorporation). These facts do not mean that the data presented in this paper need not be explained; they still show what they show: proper names can be predicates. See Sect. 7.4 for discussion.
} 
$\mathrm{DP}_{2}$ is introduced by a (dative) preposition (e.g. Hebrew $k-r-h$ 'call', English promote) will also be left aside, though this might be too much of a simplification.

$2.3 \mathrm{xNP}_{2}$ is not an argument of the naming verb

It seems self-evident that the first extended noun phrase $\left(\mathrm{xNP}_{1}\right)$ in the naming and nomination constructions is syntactically an argument. It receives the same thematic role of GoAL in naming and nomination, suggesting a double-object analysis (but see Sect. 7.1); then the second $\mathrm{xNP}\left(\mathrm{xNP}_{2}\right)$ can be viewed as the THEME of this postulated ditransitive structure.

The first indication that this view is incorrect comes from the choice of the interrogative and anaphoric pronouns when $\mathrm{xNP}_{1}$ is animate: the interrogative is what or how rather than who, and the anaphor is so and that rather than any animate pronoun: ${ }^{5}$

(9) a. What $/ *$ who was Caesar nominated?

b. What $/ *$ who did they christen the boy that Mr. Earnshaw found?

(10) Latimeria is called latimeria/that/so/*it/*itself after Miss Marjorie CourtneyLatimer.

Examples (9) confirm that the proper name in the naming construction does not have the same meaning as the proper name in an argument position: this is why the anaphoric pronoun is not animate. The fact that no referring pronoun (not even an inanimate anaphor like itself) can appear as $\mathrm{xNP}_{2}$ argues that $\mathrm{xNP}_{2}$ does not refer to an individual, but does not in itself show that $\mathrm{xNP}_{2}$ is a predicate. ${ }^{6} \mathrm{~A}$ stronger argument comes from the behavior of proper names in clefts. As observed by Jackendoff (1977) and Stowell (1981), some constituents can be clefted and others cannot:

(11) a. It was [ NP your book about the double helix ] Stowell (1981, p. 24) that I wanted.

b. It was [ PP under the chair ] that I think I left my coat.

c. *It was [ vp go home early ] that John did.

d. *It was [ AP very angry at me ] that John was.

Stowell (1981) argues that the constraint is categorial: only [- V] projections can be clefted. He further claims that the constraint cannot be attributed to a semantic or pragmatic restriction because pseudo-clefts, whose semantics is very similar to that of clefts, are not restricted in this way. However, there are reasons to believe that the relevant factor is likely to be semantic, since not all xNPs or all PPs behave alike. As shown by examples (12), predicate xNPs and PPs cannot be clefted:

\footnotetext{
5 I have nothing to say about why the choice of the interrogative vacillates between what and how depending on the choice of the verb (or the choice of a language), and why some verbs (e.g. rename) allow both.

6 The fact that the referential pronoun that can be used does not entail anything, since it can be used to refer to predicates in unambiguous contexts:
}

(i) My mother is a doctor and I want to become one/?that/*it as well. 
(12) a. *It was a doctor that John was.

b. *It was (the) president that Mary was.

c. *It was in the States that Lucie was.

If the possibility of clefting an XNP or PP constituent depends on whether it is a predicate (in which case clefting is impossible) or not, the fact that proper names in naming constructions cannot be clefted is highly suggestive:

(13) a. *It was John that we baptized him.

b. *It was Mary that she was called.

The parallel behavior of proper names in the naming construction and predicate common nouns suggests that in the naming construction, proper names are predicates. Further evidence in the same direction comes from the behavior of the definite article.

\subsection{Bare definites}

As mentioned above, Stowell (1989) argues that verbs of nomination appear with a small clause complement. An interesting property of these small clauses is that they can contain a bare NP predicate, which is nonetheless interpreted as definite in the sense that the NP restrictor denotes a singleton set:

(14) a. The queen appointed her lover treasurer of the realm.

b. Anne's death made George (the) king of England.

Predicates that do not denote singleton sets disallow article omission in English (though the situation is different in Romance and other Germanic languages):

(15) We named him public enemy $*($ number 1$) / *$ enemy of the state.

Stowell hypothesizes that there exists a correlation between the presence of the DP layer and the argument/predicate status of a noun phrase, with bare NPs being predicates. Although the correlation does not hold to $100 \%$, as can be seen from bare nominals in argument positions in such examples as go to school (cf. Stvan 1998, among others), it nevertheless seems reasonable to assume that a bare definite NP is likely to be a predicate. ${ }^{7}$

Setting aside the mechanism underlying the absence of the article in the predicate position, we will merely use this absence as a diagnostic for the predicate/argument status of a given xNP: if it, though semantically definite, appears without an article in a structure where another xNP can be viewed as its subject, the structure under consideration is likely to be that of a small clause.

\footnotetext{
${ }^{7}$ English is rather exceptional in that only definite predicates appear without an article. This phenomenon extends to indefinite nominal predicates in French (Kupferman 1979; Pollock 1983; Boone 1987; Longobardi 1994; Chierchia 1998; Roy 2001, among others), in Dutch (de Swart et al. 2005) and in German. I will not address the nature of the phenomenon here and use it merely as a diagnostic for predication.
} 
The connection between bare definite predicates and naming constructions lies in the fact that in languages where proper names in argument positions appear with definite articles (the so-called preproprial articles), they do not do so with verbs of naming (unless the proper name is modified). For instance, many dialects of German have this property, as in examples below, due to Nina Rothmayr, p.c.:
a. Ich habe den Karl gesehen.
I have the-ACC Karl seen
I have seen Karl.
b. Ich habe ihn (*den) Karl genannt.
I have him-ACC the-ACC Karl called
I called him Karl.

A non-Indo-European language exhibiting the same property is the Uto-Aztecan language Pima, where proper names in argument positions must appear with an article, except in sentence-initial positions, where definite articles drop in general in that language (Smith 2004):
a. John 'o ñeid heg Mary.
John AUX:IMP see DET Mary
John sees Mary.
b. Mary 'o ñeid heg John.
Mary AUX:IMP see DET John
c. Neid 'o heg John heg Mary.
see AUX:IMP DET John DET Mary

As can be seen from examples (18), due to Marcus Smith, p.c., when the proper name the Apaches appears in the naming construction, the article disappears:
a. Hegam Pimas gamhu ha'ab 'ab 'e- 'a'aga 'oob. Pima those Pimas over.there side DX ANA- say Apache

Those Pimas on the other side [of the border] call themselves Apache.

$\begin{array}{lllllll}\text { b. M } & \text { 'ac } & \text { 'aacim } & \text { 'ab } & \text { 'ep 'i } & \text { ha- 'a'aga heg } \\ \text { DX } & \text { AUX:1PL } & \text { we } & \text { DX } & \text { too INCEP } & \text { 3PL- say } & \text { DET } \\ \text { 'o"ob } & \text { 'i } & \text { ha'ab } & \text { 'oob. } & & & \\ \text { PL.Apache } & \text { here } & \text { side Apache } & & \\ \text { We also call the Apaches on this side [of the border] Apache. }\end{array}$

Tagalog xNPs (including proper names) require a determiner, which takes a special form with proper names. xNPs can be bare only in the predicate position and in a particular existential construction (Norvin Richards, p.c.):
Kalabaw
si
Marcos.
water-buffalo the.PRPR Marcos
Marcos is a water buffalo.

Tagalog: predication

The special preproprial definite article disappears in the naming construction, which can thus be assimilated to other instances of predication: 
(20) Pinangalanan ko siyang Alice.

naming named I her-LNKR Alice

I named her Alice.

Catalan (data due to Louise McNally and Maria Núria Martí Girbau, p.c.) also has a special definite article used with proper names. This article disappears when the proper name appears in a naming construction, as shown by the contrast between $\mathrm{xNP}_{1}$ and $\mathrm{xNP}_{2}$ in $(21):^{8}$

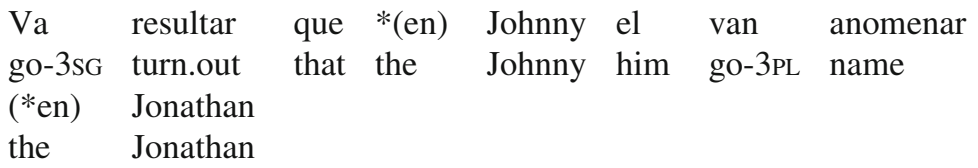

It turned out that Johnny had been named Jonathan.

Likewise, in colloquial Icelandic, Northern Norwegian and Northern Swedish argument proper names also require a preproprial article (Delsing 1993, p.54). In Northern Norwegian, the preproprial article takes the form of a third person pronoun (data and judgments due to Peter Svenonius and Øystein Alexander Vangsnes, p.c.):
a. Ho Marit så han Øystein.
she Marit saw he Øystein
Marit saw Øystein.
b. Han Øystein så ho Marit.
he Øystein saw she Marit
Øystein saw Marit.

In naming constructions (as well as some others, such as vocatives, play-acting and certain possessives) this preproprial article disappears (Delsing 1993):
a. Dæm døpte barnet (*ho) Marit. they baptized child.the (she) Marit They baptized the child Marit.
b. Han heter (*han) Øystein.
he is.called he Øystein
He is called Øystein.
naming

If proper names in naming constructions are used predicatively, the lack of the article can be explained by analogy with bare predicate definites in (14). However, the lack of the article does not by itself argue in favor of the theory that proper names are predicates in naming constructions. Indeed, one could argue that the reason for article absence is non-referentiality. Then proper names could appear bare in naming constructions not because they are predicates but because they are not referential - something fully consistent with the hypothesis that naming

\footnotetext{
8 The feminine preproprial article $n a$ is only preserved in the more conservative dialects, such as the Balearic Catalan-other dialects use the regular feminine article la (Maria Núria Martí Girbau, p.c.). See Longobardi (1999) and Coromina i Pou (2001) for some discussion of Catalan, and Campbell (1991), as cited by Delsing (1993) on the subject of special preproprial articles in Tagalog, Malagasy, and Maori.
} 
constructions involve "mention" rather than "use" of proper names. The crosslinguistic data that we will consider next are, however, incompatible with the assumption that the proper name in the naming construction is a phonological string that is an unanalyzable quote of the name itself, i.e., that Alice in the naming construction means /ælıs/ and nothing more.

\subsection{Predicate marking}

In Korean, proper names in naming constructions appear with the copula (Shin-Sook Kim, p.c.):
a. ku-nun caki-uy ttal-lul Miran-i-la-ko
pwull-ess-ta. he-TOP self-GEN daughter-ACC Miran-be-ASSERTIVE-QUOT call-PST-DECL He called his daughter Miran.
b. salam-tul-un ku-lul hankwuk-uy Elvis-i-la-ko pwull-ess-ta. person-PL-TOP he-ACC Korea-GEN Elvis-be-ASSERTIVE-QUOT call-PST-DECL People called him the Korean Elvis.

The presence of the copula $-i$ cannot be squared with either the simplex "mention" theory or with the view that proper names in naming constructions denote something like "the name X", since in neither of these two approaches is a copulative element expected to appear.

The same kind of evidence can be drawn from the distribution of the predicative particle $y n$ in Welsh, which is obligatory in small clauses (Bowers 1993; Rouveret 1994, 1996; Zaring 1996, among others):

$$
\begin{aligned}
& \text { a. Mae Siôn *(yn) ddedwydd. } \\
& \text { is Siôn PRT happy } \\
& \text { Siôn is happy. } \\
& \text { b. Y mae Siôn yn feddyg. } \\
& \text { PRT is Siôn PRT doctor }
\end{aligned}
$$

Sion is a doctor.

Welsh is like English in that definite predicates appear without an article, but if a DP is marked definite, $y n$ cannot appear because a different (equative) construction is used (Rouveret 1994). With naming verbs, proper names behave like semantically definite but syntactically bare nominal predicates, appearing with the predicative particle yn (Alain Rouveret, p.c.):

(26) Enwyd ef yn Siôn arôl ei dad. name-PASS he PRT Siôn after his father He is named Siôn after his father.

Obviously, the presence of the copular particle naturally follows from the hypothesis that the proper name is a predicate here and seems inexplicable otherwise. Even stronger evidence for a small clause analysis of naming constructions comes from languages with morphological case-marking. 


\subsection{Case-marking}

In languages where predicates are marked with a particular case, the case on $\mathrm{xNP}_{2}$ in naming constructions is that of a predicate. Such predicative case-marking falls into two categories: dedicated predicative case and case agreement.

\subsubsection{Predicative case}

The languages to be considered in this subsection are Hungarian, Finnish, Arabic and Russian. While none of these three languages has a dedicated case used only with predicates, predicates are nonetheless consistently marked with a particular case (dative, accusative and instrumental, respectively). This case-marking extends to naming constructions.

In Arabic the predicative case is accusative, as shown by the ECM and nomination constructions below (examples due to Nisrine Al-Zahre). The passivized variant is there to show that accusative is not copied from the case of $\mathrm{xNP}_{1}$ (case agreement):

$$
\begin{array}{llll}
\text { salma } & \text { iftabarat } & \text { walad-a-ha } & \text { wazir-an. } \\
\text { Salma } & \text { consider-PRF } & \text { child-ACC-her } & \text { minister-ACC }
\end{array}
$$

Salma considered her child to be a minister.
a. salma fayyanat
walad-a-ha
wazir-an.
salma nominate.CAUS-PRF child-ACC-her minister-ACC
nomination
Salma nominated her child to be a minister.
b. walad-u-ha iuyyna wazir-an.
child-NOM-her nominate.PASS-PRF minister-ACC
Her child was nominated to be a minister.

As expected, in naming constructions, $\mathrm{xNP}_{2}$ is also marked accusative:
a. salma laqqabat
walad-a-ha
Saliy-an.
salma nickname.CAUS-PRF child-ACC-her Ali-ACC
Salma nicknamed her child Ali.
b. walad-u-ha luqqiba ialiy-an.
child-NOM-her nickname.PASS-PRF Ali-ACC
Her child was nicknamed Ali.

In Hungarian, xNP predicates are marked dative, as shown by the resultative construction in (30a) and the nomination construction in (30b) (data due to Veronika Hegedüs and Gabriella Tóth):
a. Az anyja
tanárnak
tanítatja
Pétert.
resultative
the mother-his teacher-DAT learn-make Peter ACC
His mother makes Peter learn to become a teacher.
b. A lány- om-at elnök-nek jelölt-em.
the daughter 1sG-ACC president-DAT nominated-1SG
I nominated my daughter president.
nomination 
In Hungarian naming constructions $\mathrm{xNP}_{2}$ bears dative and $\mathrm{xNP}_{1}$ is marked with accusative:

$$
\begin{array}{lllllll}
\text { a. A lány- } & \text { om-at } & \text { Mari- } & \text { nak } & \text { nevezt-em } & \text { el. } \\
\text { the daughter } & \text { 1sG-ACC } & \text { Mary- } & \text { DAT } & \text { named-1SG } & \text { PREVERB }
\end{array}
$$
I named my daughter Mary.

This is the exact reverse of what happens in ditransitives (dative on the GoAL, accusative on the THEME), showing that naming constructions project a different structure.

In Finnish, $\mathrm{xNP}_{2}$ in naming constructions is marked with the translative case, which is the case marking resultative predicates in change-of-state constructions (Fong 2003, examples due to Liina Pylkkänen, p.c.):

a. Me valits-i-mme $\quad$ Sue-n $\quad$ presidenti-ksi.

nomination

We elected Sue president.

b. Me maalas-i-mme seinä-n keltaise-ksi.

resultative

we paint-PST-1PL wall-ACC yellow-TRS

We painted a/the wall yellow.

Case-marking in Finnish being partly semantic, $\mathrm{xNP}_{2}$ in naming constructions is marked translative, rather than essive (the case of primary predication not involving a change of state).
Me kutsu-mme William Gatesi-a
Billi-ksi.
Finnish: naming
we call-1PL
William Gates-PART
Billy-TRS
We call William Gates Billy.

In Russian (and many other Slavic languages) predicates are marked instrumental (Bailyn and Rubin 1991; Bailyn and Citko 1999; Pereltsvaig 2001, among many others):
a. Ja sčitaju
ee
lingvistkoj.
I consider her-ACC
I consider her a linguist.

ECM

b. Ona vernulas' krasavicej.

depictive she came back beauty-INSTR

She came back a beauty.
a. Senat
izbral
Cezar'a
konsulom.
nomination
Senate-NOM chose-M Caesar-ACC
The Senate elected Caesar consul.
b. Cezar' byl izbran konsulom.
Caesar-NOM was-M chosen-M consul-INSTR
Caesar was elected consul.


In naming constructions, $\mathrm{xNP}_{2}$ can be marked instrumental as well:

(36) Ee okrestili Annoj.

naming

3FSG-ACC baptized-PL Anna-INSTR

They baptized her Anna.

Russian differs from Hungarian and Arabic in that with the default verb zvat' 'call' and some of its derivates, $\mathrm{xNP}_{2}$ can also be marked nominative:
a. Moju sestru zovut Nina/Ninoj.
my sister-ACC call-3PL Nina-NOM/INSTR
My sister is called Nina.

b. Septimija prozvali Sever/Severom.

Septimius-ACC nicknamed-PL Severus-NOM/INSTR

Septimius was nicknamed Severus.

$\begin{array}{lll}\text { c. Ego } & \text { obozvali } & * \text { plaksa/ } \checkmark \text { plaksoj. } \\ \text { 3MSG-ACC } & \text { dubbed-PL } & \text { crybaby-NOM/INSTR }\end{array}$

He was stigmatized as a crybaby.

There is some difference in meaning between nominative and instrumental, but it is very elusive, and the entire phenomenon resembles that of the nominative/ instrumental variation with the copula be (Bailyn and Rubin 1991; Bailyn and Citko 1999; Pereltsvaig 2001, among others). ${ }^{9}$ As suggested by David Pesetsky, p.c., the nominative case-marking here is probably the nominative of direct quotation, as indicated by examples like (38):

(38) Liza nazyvaet svoju sestru moja radost'/*mojej radost'ju.

Lisa calls self's sister my joy-NOM/INSTR

Lisa calls her sister "my joy".

The first person pronoun in (38) is interpreted as referring not to the speaker of the utterance, but rather to the subject of naming verb (i.e., Lisa's sister), which means that the entire expression is used quotatively.

Furthermore, with proper names that are not names of humans or animals only nominative is allowed in naming constructions (many thanks to Barry Schein for drawing my attention to this fact):

(39) Tolstoy nazval svoj roman Anna Karenina/*Annoj Kareninoj.

Tolstoy called self's novel Anna Karenina-NOM/InstR

Tolstoy called his novel "Anna Karenina".

The unavailability of instrumental case-marking may correlate with the fact that inanimate individuals such as books are never properly "called" or "addressed" by their names, though I cannot offer any formal account of this phenomenon.

\footnotetext{
9 Czech also allows the two cases in naming constructions and with the copula be; instrumental is interpreted as more temporary (Hana Skrabalova, p.c.).
} 


\subsubsection{Case agreement}

Case agreement is a phenomenon whereby the structural case assigned to the subject (nominative or accusative) is shared by the predicate. This means that it is a characteristic property of small clauses. ${ }^{10} \mathrm{I}$ will not be concerned with the syntactic mechanism underlying case agreement here (see Maling and Sprouse 1995; Frampton and Gutmann 2000; Bailyn 2001; Chomsky 2001; Matushansky 2008 for some discussion), but will merely use it as a diagnostic for a small clause structure.

An example of a language with case agreement is Latin. In Latin small clauses, the case on the predicate is the same as that on $\mathrm{xNP}_{1}$ : when passivization renders $\mathrm{xNP}_{1}$ nominative, this is reflected in the case of the predicate:

a. Ciceronem clarum habent.

small clause

Cicero-ACC famous-ACC consider/hold

They consider Cicero famous.

$\begin{array}{ll}\text { b. Cicero clarus } & \text { habetur. } \\ \text { Cicero-NOM famous-NOM } & \text { consider/hold-PASS } \\ \text { Cicero is considered famous. }\end{array}$

passive
a. Ciceronem consulem facit.
Cicero-ACC consul-ACC make-3sG
S/he makes Cicero consul.
b. Cicero fit consul.
Cicero-NOM is.made-3sG consul-NOM
Cicero is made consul.

verb of nomination

The fact that case agreement also takes place with naming constructions suggests that verbs of naming take small clause complements:
a. Filium meum Lucium voco.
son-ACC my-ACC Lucius-ACC call-1sg
I call my son Lucius.
b. Meus filius vocatur Lucius.
my-NOM son-NOM call-PASS-3sG Lucius-NOM
My son is called Lucius.
verb of naming

There is no accepted theory of case agreement, but while "copying" the case of the subject onto the predicate can be viewed as a kind of agreement, no relation is commonly assumed to exist between two internal arguments of a ditransitive verb that would permit to connect their case-marking. In other words, case agreement is only compatible with a theory where $\mathrm{xNP}_{2}$ is a predicate.

\footnotetext{
${ }^{10}$ Case agreement also occurs in Japanese and Korean with inalienable possession, and Massam (1985) and following her Cho (1998) argue that inalienable possession in Korean involves ECM. Although, interestingly, one of the contexts in Northern Norwegian where the preproprial article disappears is possession, it is quite likely that the two phenomena are completely different. I will not pursue the matter any further here.
} 
Another language with case agreement is Icelandic (Maling and Sprouse 1995):

a. Hún er kennari/*kennara.

Maling and Sprouse (1995, p. 168)

he is teacher-NOM/ACC

He is a teacher.

b. Ég taldi hana/*hun vera Maling and Sprouse (1995, p. 170)

I believed her-ACC/NOM to-be

kennara/*kennari.

teacher-ACC/NOM

I believe her to be a teacher.

As expected, with respect to case agreement Icelandic verbs of naming behave like ECM verbs (examples due to Thorbjörg Hróarsdóttir):
a. Ég kallaði/ skírði dóttur mína Herborgu.
I called/ baptized daughter-ACC 1sG.POSs-ACC Herborg-ACC
I called/baptized my daughter Herborg.
b. Dóttir mín er kölluð Herborg.
daughter-NOM 1sG.POSS-NOM is called Herborg-NOM My daughter is called Herborg.
c. Yngri dóttir mín var skírò Vigdís. younger daughter-NOM 1sG.POSS-NOM was babtized Vigdís-NOM My younger daughter was baptized Vigdis.

The same effects obtain in Modern Greek (examples due to Dimitra Papangeli):
a. Theoro
to
Yani
ilithio.
ECM
consider-1sG the.ACC Yani-ACC idiot-masc-ACC
I consider Yani an idiot.
b. $\mathrm{O}$ Yanis theorite ilithios. passive the.NOM Yanis-NOM consider-PASs.3sG idiot-NOM Yani is considered an idiot.

(46)
a. Diorisa
to
Yani
diefthindi.
nomination
appointed-1SG the.ACC Yani-ACC director-ACC
I appointed Yani (the) director.
b. $\mathrm{O}$ Yanis dioristike diefthindis passive the.NOM Yanis-NOM appoint-PASs.3sG director-NOM
Yani was appointed (the) director.

As examples (45) and (46) show, besides being a case agreement language, Modern Greek also necessitates an article for proper names in argument positions. In naming constructions, the definite article on $\mathrm{xNP}_{2}$ disappears and the case on $\mathrm{xNP}_{2}$ is the same as that on $\mathrm{xNP}_{1}$ : 

a. Vaftisa
to Yani
Petro.
naming
baptised-1sG the.ACC Yani-ACC Petro-ACC
I baptized Yani Petro.
b. $\mathrm{O}$ Yanis vaftistike Petros.
the.NOM Yanis-NOM baptise-PASs.3sG Petros-NOM
Yani was baptized Petro.

In other words, both predicate diagnostics suggest that the naming construction in Modern Greek involves a small clause.

\subsection{Other predicate positions}

If there are ECM verbs of naming, there should be raising verbs of naming, such as the Dutch heten (Eddy Ruys, p.c.) and the German heissen 'to be called':

(48) $\mathrm{Zij}$ heet Marie.
she is.named Marie
She is named Marie.

Dutch

She is named Marie.

Further evidence in favor of our hypothesis comes from the fact that proper names can also appear as secondary predicates and complements of other ECM verbs (see also Bach 2002), as well as in apposition: ${ }^{11}$

(49) a. Born [PRO Charles Lutwidge Dodgson], the man who would become Lewis Carroll was an eccentric and an eclectic.

b. The first president of the United States, George Washington, was born in February.

The general analysis of depictives is that they appear in the predicate position of a small clause with a PRO subject. If a proper name appears as a secondary predicate, this means that it can function as a predicate. Likewise, the fact that a proper name can appear with become or make, which are commonly assumed to combine with small clauses, shows that it can function as a predicate in this environment as well. A similar reasoning applies to appositives.

A possible objection to be raised at this point is the absence of extended VP complements to verbs of naming. While most ECM, raising and nomination verbs allow infinitival, indicative or subjunctive complements (sometimes with a subtle change in meaning), verbs of naming can only appear with a nominal small clause,

\footnotetext{
11 Proper names cannot appear with verbs like seem or believe. Two possible explanations can be envisaged: (1) These verbs impose a scalarity constraint on their complement (Matushansky 2002b), to which proper names do not conform, and (2) proper names have no possible world argument slot and therefore do not form small clauses that could appear as complements to intensional verbs. See also Sect. 4.2 for the discussion of the unavailability of de dicto readings for proper names.
} 
as shown by the contrast between the nomination verbs in (50) and the naming verb in (51):

(50) a. They proclaimed Arthur to be the king of all England.

infinitival

b. The prince declared that the war was inevitable.

c. Gawaine chose that Dame Ragnell be a beauty indicative by day and a hag by night.

subjunctive

(51) a. Earnshaw named the foundling Heathcliff.

b. *Earnshaw named the foundling (to) be Heathcliff.

c. *Earnshaw named that the foundling is/be Heathcliff.

I can envisage two explanations, a syntactic one, which I find uninteresting, and a semantic one, which seems to be less arbitrary, but has the problem of predicting uninterpretability rather than ungrammaticality.

The syntactic explanation capitalizes on the fact that a head can c-select its complement. Thus no verb of perception, for example, allows infinitival complements, but finite complements are permitted with all of them and some also permit small clause ones:

(52) a. Carol saw that the sentinel had left.

b. Carol saw Claire running/run/*to run.

small clause/xVP/*IP

It is possible therefore that verbs of naming restrict the lexical category of the predicate of the small clause they combine with to xNPs only. Examples such as (53) show that other ECM verbs can categorially restrict the predicate of their small clause (cf. Stowell 1981, 1983):

(53) a. I consider Elizabeth $\checkmark$ clever $/ \checkmark$ a friend $/ \checkmark$ in the running/*(*to) live in Paris.

b. I let Elizabeth $*$ clever/*a friend $/ \checkmark$ into the house $/ \checkmark$ (*to) live in Paris.

c. I made Elizabeth $\checkmark$ clever $/ \checkmark$ a professor/*into the house $/ \checkmark$ (*to) live in Paris.

The alternative is that a verb, as in (51b) and (51c), would introduce an event argument, which is incompatible with the semantics of both proper name small clauses (on which below) and naming verbs. This solution has more to recommend itself, since the semantics of naming verbs that we propose below does indeed make them incompatible with event complements, but it predicts that $(51 \mathrm{~b}, \mathrm{c})$ should be uninterpretable rather than ungrammatical.

\subsection{Interpretation}

The final piece of evidence in favor of analyzing proper names in the naming construction as predicates and against a ditransitive analysis, which would treat proper names as "mentions" or unanalyzable quotes, comes from the interpretation of the proper name in these constructions.

Suppose that the naming construction indeed involved a simple mention of a proper name, just like examples (54) do: 
(54) a. (The word) fry has three letters.

b. A hand wrote (the words) Mene, mene, tekel, upharsin on the wall.

The italicized expressions in (54) involve mention rather than use, as can be shown by the fact that they can be preceded by such explicit indications of their metalinguistic status as "the word(s)", "the expression", etc. However, a proper name $\mathrm{X}$ cannot be replaced with the/a name (of) $X$ in naming constructions, which means that $\mathrm{X}$ does not denote the name $X$ :

They named him (*the name (of)) Heathcliff.

If the naming construction did in fact require a mention of the proper name, such mention could have been made explicit. The fact that it is impossible suggests that the proper name here is not used as a quote. ${ }^{12}$

\subsection{Summary}

I argued, on the basis of the following cross-linguistic generalizations that verbs of naming (like verbs of nomination and other clearly ECM verbs) take a small clause complement:

- The definite article on the predicate proper name is dropped in naming constructions just as it is dropped with definite predicates

- $\quad$ Case-marking of the proper name parallels that of a predicate (the predicative case or case agreement, depending on the language)

- $\quad$ Proper names can function as predicates without a naming verb

Evidence against alternative syntactic analyses can be found in the Appendix.

Importantly, there is nothing about the semantics of the naming construction that requires it to be analyzed as involving predication. It is the cross-linguistic syntactic evidence that rules out semantic analyses where proper names are treated as

12 One potential counter-example due to Roger Schwarzschild, p.c., involves the default verb call:

(i) She called him every name in the book.

This example (under the assumption that it can have the non-idiomatic reading) raises two separate problems. On the one hand, it would seem that a proper name can after all be replaced by a regular xNP. On the other, how can a predicate be universally quantified? To answer these questions we compare the construction in (i) to that in (ii), which also has a predicational meaning and contains universal quantification (see Partee 1986 answering Williams 1983):

(ii) This house has been every color.

Both (i) and (ii) are English-specific. The similarity between the two argues in favor of our theory, because it means that the default naming verb call shares some properties with the copula be. Nonetheless, given how often call has special syntax, we do not consider this result important. Furthermore, as Philippe Schlenker (p.c.) notes, a straightforward naming counterpart of (ii) is impossible:

(iii) * She has been every name.

One possible explanation of this fact is that the noun name in itself is not a predicate proper name (in the sense to be made precise below) and so cannot be used to substitute for one. Much more likely is the hypothesis that the example in (i) is as idiomatic as it seems, and therefore should not even be considered. 
unanalyzable quotes or mentions (along the lines of "(the phonological string or sound) /ælis/").

We hypothesize that proper names in argument positions should incorporate the meaning that they have in the predicate position, just like definite argument DPs incorporate the meaning of corresponding NP predicates. Two sides of the question must be taken into account: on the one hand, proper names are predicates, but on the other hand, they must be sufficiently different from common nouns to explain such differences between the two as the ability to appear with verbs of naming (excluded for common nouns) and the de dicto reading (generally considered impossible for proper names).

\section{The basics of the analysis}

The goal of this section is to provide a lexical entry for proper names, which will serve as a basis for the analysis proposed below. Since we will assume, on the basis of the data provided above, that proper names enter syntax as predicates, we will be able to account for modified and complex proper names in a way parallel to modification inside DPs. I will show that proper names are more than simple one-place predicates, and need to incorporate into their meaning a naming convention (to be defined below). As a result, we will also be able to account for certain peculiarities of the behavior of proper names in argument positions.

The appearance of proper name predicates in the naming construction allows us to immediately discard the class of hypotheses where proper names in argument positions are constructed on the basis of artificial predicates making reference to the denotation of a proper name, such as $\lambda x . x=$ Alice, or are abbreviated definite descriptions of the kind Aristotle = "the one who Aristotelizes". Neither of such artificial predicates gives us the right meaning in naming constructions.

Closer to the correct result is the hypothesis advocated, among others, by Bach (1981, 1987, 2002), Geurts (1997) and Recanati (1997), where the lexical entry of a proper name approximates the meaning of a common noun, as in (56). However, in Sect. 4.2 below I will show that such a simple predicate is not sufficient.

$$
\text { [Cate }]=\lambda \mathrm{x} \cdot \mathrm{x} \text { is an entity named } / \mathrm{ke}^{\mathrm{j}} \mathrm{t} /
$$

The presence of the 'named $X$ ' component in the meaning of a proper name immediately explains why, for every proper name in an argument position, an inference can always be made that the individual that this proper name denotes bears that particular proper name:

$$
\begin{aligned}
& \text { Lisa came home. } \\
& \Rightarrow \exists x \text { [x is named Lisa \& } \mathrm{x} \text { came home }]
\end{aligned}
$$

However, I believe that the lexical entry in (56) needs to be further decomposed, with the relation of naming (or nicknaming or baptizing) viewed as another argument of the proper name, as presented in (58). I propose that proper names are 
two-place predicates: ${ }^{13}$ besides the standard individual argument slot, they also have an argument slot for the naming convention $R$ (a notion introduced by Recanati (1997) that will be made precise below):

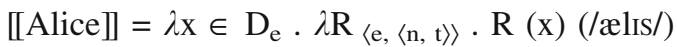

where $\mathrm{n}$ is a sort of the type e (a phonological string)

I will argue below that when a proper name functions as the predicate of a small clause in the complement of a naming verb, it is the verb itself that supplies the naming convention. On the other hand, when a proper name appears in an argument position, the argument slot for the naming convention is saturated by a free variable-the contextually salient naming convention in force between the speaker and the hearer, or more strictly speaking, the naming convention of the speaker that is presupposed to be shared by the hearer. Thus the meaning of a proper name in an argument position, once the argument slot for the naming convention has been saturated (see Sect. 4.1 for details and technicalities), becomes close if not identical to that in (56):

(59) [Alice] $\left(\mathrm{R}_{0}\right)=\lambda \mathrm{x} \in \mathrm{D}_{\mathrm{e}} \cdot \mathrm{R}_{0}$ holds between $\mathrm{x}$ and the phonological string /ælis/ where $\mathrm{R}_{0}$ is the contextually salient naming convention in force between the speaker and the hearer

The lexical entry in (58) means that the contents of the name quotes the (phonology of) the name itself, which makes my approach a special case of the so-called "quotation theories" of proper names (cf. Kneale 1962; Bach 1981, 1987, 2002; Geurts 1997). This reference to phonology is essential, because phonology is the only clue that allows us to distinguish different proper names (Sylvain Bromberger, p.c., see also the discussion in Abbott (2005). ${ }^{14}$

\subsection{The naming convention}

The lexical entry in (56) becomes problematic only in the naming construction. The question that arises when we try to use it there is that of how to specify the fact that the meaning of the naming verb (or of its root) is what determines the relation between the subject and the predicate of the small clause. In other words, if (60a) holds, then the phonological string / $\mathrm{gre}^{\mathrm{j} /}$ is the name of this girl, while if $(60 \mathrm{~b})$ holds, then the relation between the two is that of nicknaming.

(60) a. This girl is named Grey.

b. This girl is nicknamed Grey.

\footnotetext{
13 Though the word "predicate" is often used to denote one-place functions, I follow here the more lax usage, which also permits to treat scalar adjectives as predicates, despite the additional argument slot for the degree.

14 Consequently, phonological strings become themselves objects in the model. I set this complication aside here as not directly relevant, but will presuppose that they belong to the sort $n$ of the semantic type $e$.
} 
Since the lexical entry in (56) explicitly specifies the relation between the proper name (the phonological string) and its bearer as that of naming, no room is left for maneuver. I propose to make this room by making the nature of the naming convention holding between a proper name and its potential bearer variable.

As is easy to see, a naming convention is a relation between a phonological string and an entity that bears that phonological string as its proper name due to this naming convention. Can more be said about the formal nature of this relation? In particular, can naming conventions be characterized as functions from entities to phonological strings, functions from phonological strings to entities or even bijections? I believe that the answer is negative.

\subsubsection{Functions from phonological strings to entities}

Under this view, each proper name has only one bearer, though an individual may bear more than one proper name. In fact, the cross-linguistic syntax of proper names appears to presuppose that each proper name is only associated with one individual: proper names behave as definites by default and appear with an indefinite article (or other determiners) as a marked option.

In languages, where proper names must appear with an article, like common nouns (as in Modern Greek and Albanian below), by default the article is definite:
a. Theoro
to
Yani
ilithio.
consider-1sG the.ACC Yani-ACC idiot-masc-ACC
I consider Yani an idiot.
b. Ron-a
konsidero-hej
student-ja
më e mirë
Rona-the.NOM
e klasës.
AGR class-the.DAT

Rona was considered the best student in class.

Conversely, cases like (62) and (63) are in no way default and are perceived as marked:

(62) a. There are relatively few Alfreds in Princeton.

Burge (1973)

b. Some Alfreds are crazy; some are sane.

The indefinite article, universal quantifiers and demonstratives (in particular, the so-called expressive that; see Barker 1998) are also possible:

a. There's a Mr. Smith to see you, sir.

b. This Rover of yours has overturned the garbage again!

c. Every John Smith hates his name.

Whereas the hypothesis that naming conventions are functions from phonological strings to entities does entail that they should appear with definite articles, it cannot explain why cases like (62) and (63), where proper names combine with indefinite 
articles and other determiners, are possible at all. In addition it predicts that individuals may not share a name received by the same convention, which is patently false.

Likewise, this hypothesis cannot deal with complex proper names, like Lucy Smith (see Sect. 4.4). In the first place, if Lucy $\left(\mathrm{R}_{0}\right)$ denotes a singleton set (as predicted by this hypothesis), then the surname Smith should have been treated as an appositive. A possible "solution" to this problem would have been to treat the complex proper name Lucy Smith as morphologically, syntactically and semantically simplex. Introspectively, however, a person uttering Lucy Smith is aware of the fact that both Lucy Smith is named Lucy and is, furthermore, not uncomfortable with the existence of Lucy Brown, which means that the proper name Lucy is associated with more than one individual. Likewise, restrictively modified proper names, such as (64), are predicted to be impossible:

\section{Q: Which Lucy do you mean?}

\section{A: The tall Lucy.}

We conclude that the hypothesis that naming conventions are functions from phonological strings to entities, however attractive it seemed, must be set aside. This also means that naming conventions cannot be bijective.

\subsubsection{Functions from entities to phonological strings}

Under this view, once the naming convention has been selected, each individual only bears one proper name. Once again, this assumption is inherently problematic, though less so than the previous one. First of all, examples like (65) suggest that the same individual can be associated with more than one name, even by the same speaker:

(65) She was Lo, plain Lo, in the morning, standing four feet ten in one sock. She was Lola in slacks. She was Dolly at school. She was Dolores on the dotted line. But in my arms she was always Lolita (Vladimir Nabokov, Lolita).

It could be argued that (65) involves more than one naming convention. It does not seem illogical or wrong to assume that naming conventions can be pragmatically sensitive, and (65) reflects such sensitivity. However, once again complex proper names pose a problem. The fact that an individual is named Lucy Smith would seem to preclude its being named Lucy-which, once again, contradicts our intuitions.

Finally, the hypothesis that naming conventions are functions from entities to phonological strings cannot explain why proper names are inherently definite, which means that there are few advantages attached to adopting it. We therefore conclude that naming conventions do not seem to be functions in either direction.

\subsubsection{The nature of the naming convention}

It would seem that neither of the two hypotheses advanced in the beginning of this section should be adopted, as both are fraught with problems: while 
cross-linguistically proper names behave in argument positions as if they were underlyingly singleton sets, in practice such is demonstrably not the case (as has been extensively discussed in the literature): there clearly are several Johns and more than one Mary in the world, as is also illustrated by the possibility of using a proper name with an article other than the definite one in (62) and (63) and the entailments arising from the use of complex or modified proper names.

In short, whereas the observed cross-linguistic syntax of proper names suggests that the relation between names and individuals that bear them is a function, such a conclusion seems to be too strong for the lexical semantics of proper names in the general case.

This is why I propose to treat naming conventions as relations between individuals and proper names: one individual may bear more than one name and a given proper name may be associated with more than one individual. The latter is particularly clear for surnames, on which more in Sect. 4.4 below.

If a naming convention is a relation between individuals and proper names (phonological strings, properly speaking), no special proviso must be made to explain why an individual may have more than one name, or why there may be complex proper names. In order to motivate the definite article it becomes necessary to use covert domain restriction à la von Fintel 1994 (cf. Bach 1981); for proper names in argument positions definiteness is therefore achieved in more or less the same way as for contextually restricted definite descriptions. The only problem with this tactics is that no explanation is given for the cross-linguistically default character of the definite article-in the approach proposed here there should be no difference between proper names and common nouns. Since I can offer no straightforward solution for this problem, I leave it for future research.

\section{Argument proper names}

The behavior of proper names in the naming construction shows that they can enter syntax as predicates, just as common nouns do. It therefore seems probable that in argument positions they behave exactly like common nouns, and that conversion from the predicate type to the argument types $e$ and $\langle\langle\mathrm{e}, \mathrm{t}\rangle, \mathrm{t}\rangle$ is accomplished by the same means. In other words, when proper names are interpreted as definite, they are in fact definite descriptions:

(66) a. A Jane Smith is here to see you. existential quantifier or choice function b. The Alice is here. iota operator

The proposal that in their most familiar meaning proper names are definite descriptions is in itself not new. On the one hand, many syntactic and semantic arguments in favor of this view, some of which will shortly be presented, have been advanced. On the other hand, a number of proposals have been made as to the exact nature of the predicate serving as a basis for these definite descriptions.

In this section I will show how the proposed lexical entries for proper names can account for their behavior in argument positions. I will demonstrate that we can deal 
successfully not only with the general rigidity of proper names, noted by Kripke (1980), but also with cases where proper names do not behave rigidly (Geurts 1997; Elbourne 2002). In addition, this proposal will make it possible for us to sketch a possible analysis of complex and modified proper names, such as Alice Liddell and the famous detective Sherlock Holmes.

\subsection{The semantics of proper names in argument positions}

The proposal that proper names are underlyingly predicates is not new, nor is the hypothesis that their meaning incorporates the notion of "being named". Thus Geurts (1997) proposes that proper names have the meaning in (56):

(56) $[$ Cate $]=\lambda x \cdot x$ is an entity named $/ \mathrm{ke}^{\mathrm{j}} \mathrm{t} /$

It is easy to see that the lexical entry in (58) is very close to that; the only difference is that in (56) the relation between the proper name $/ \mathrm{ke}^{\mathrm{j}} \mathrm{t} /$ and its bearer is that of naming, whereas in (58) it is left undetermined. Depending on what sort of a relation saturates the $\mathrm{R}$ argument slot, the phonological string/ælis/ and the entity that this string can be used to refer to (the external argument of the predicate) can stand in the relation of naming, nicknaming, baptizing, or other, linguistically unspecified naming practices (cf. ex. (65)).

$$
\begin{aligned}
& \llbracket \text { Alice }]=\lambda \mathrm{x} \in \mathrm{D}_{\mathrm{e}} \cdot \lambda \mathrm{R}\langle\mathrm{e},\langle\mathrm{n}, \mathrm{t}\rangle\rangle \cdot \mathrm{R}(\mathrm{x})(/ \mathrm{el} \text { IS/) } \\
& \text { where } \mathrm{n} \text { is a sort of the type e (a phonological string) }
\end{aligned}
$$

Thus once the naming convention argument slot is saturated, the meaning of the resulting predicate is identical or very similar to what Geurts proposes:

a. [Alice] $\left(\mathrm{R}_{1}\right) \approx \lambda \mathrm{x} \in \mathrm{D}_{\mathrm{e}} \cdot \mathrm{x}$ is called /ælıs/

b. [Alice] $\left(\mathrm{R}_{2}\right) \approx \lambda \mathrm{x} \in \mathrm{D}_{\mathrm{e}} \cdot \mathrm{x}$ is named /ælıs/

c. [Alice] $\left(\mathrm{R}_{3}\right) \approx \lambda \mathrm{x} \in \mathrm{D}_{\mathrm{e}} \cdot \mathrm{x}$ is baptized /ælıs/

A note on compositionality is in order here.

It should be observed that the $e$ argument slot of the proper name is ordered before the naming convention $\mathrm{R}$ argument slot. This means that the definite article cannot straightforwardly combine with the proper name. To resolve this issue we appeal to the mechanism proposed in Heim and Kratzer (1998), where a null operator (PRO) can be freely merged inside xNPs. This operator moves, leaving behind an $e$ trace, which makes it possible for the proper name to merge with the contextually introduced free variable of the naming convention in force between the speaker and the hearer, which $I$ will indicate as $R_{0}$. The null operator is then re-merged, forcing $\lambda$-abstraction and resulting in an $\langle e, t\rangle$-type NP, which can now be combined with the definite article: 


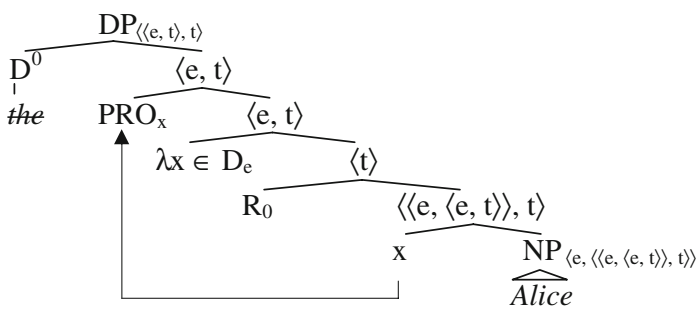

To summarize, with respect to the interpretation of proper names in argument positions this proposal presents a variation of Geurts': a proper name in an argument position consists of the definite article and a constituent denoting a property of being named so-and-so. The difference between my proposal and Geurts' is how this meaning is derived: while for Geurts the relation between the name itself (the phonological string) and its bearer is always that of naming and the proper name predicate cannot be decomposed any further, in my proposal the naming convention is a free variable introduced by the context and saturating an argument slot of the proper name predicate. While by default, what the context provides is the naming convention in force between the speaker and the hearer (cf. Recanati 1997; Pelczar and Rainsbury 1998), other naming conventions can be introduced, as will be discussed in Sect. 4.3.

The essential similarity between my proposal and Geurts' explains why our predictions for proper names in argument positions partially coincide. In particular, both proposals can address the fact that proper names appear with an overt definite article in some languages (see above) while in others some (sub-classes of) proper names (including what Strawson 1950 calls quasi-names, see Burge 1973; Geurts 1997; Elbourne 2002; Borer 2005; Matushansky 2006b) seem to contain the definite article:

(69) a. the Thames, the Pacific, the Alps...

b. the States, the Netherlands, the Sudan...

If argument proper names are derived from an underlying predicate, just like common xNPs, the presence of an article is unsurprising and it is its absence that needs to be explained. Under any other hypothesis, the has to be treated as part of the proper name, which makes it all the more strange that it disappears in exactly the same environments where the regular definite article does:

(70) a. our ugly little Thames

b. this beautiful Sudan of ours

Both proposals correctly predict the existence of definite proper names with determiners other than the, as in (70), as well as with non-definite determiners, as illustrated by (62) and (63), repeated below:

(62) a. There are relatively few Alfreds in Princeton.

Burge (1973)

b. Some Alfreds are crazy; some are sane.

c. Every John Smith hates his name. 
(63) a. There's a Mr. Smith to see you, sir.

b. This Rover of yours has overturned the garbage again!

The compositional semantics of such examples is self-evident from the discussion above on the natural assumption that these determiners behave just like the definite article.

Possibly the most interesting example of this kind is (71), where definiteness is preserved, despite the lack of the definite article. (71) does not mean "There exists no individual named Catherine that I could see", rather it means that I could not see the contextually salient Catherine.

...but no Catherine could I detect, far or near.

Emily Brontë, Wuthering Heights

A similar phenomenon can be observed with those common nouns whose extension is a singleton set (as a result of contextually introduced domain restriction):

(72) a. There is no sun today.

b. I looked all over the place - no dean!

This "definite" behavior of both proper names and common nouns can be derived from the hypothesis that quantifiers (including the negative no), like other determiners, introduce a covert restriction on their domain (von Fintel 1994).

The similarity between proper names and other definite descriptions does not end here, and Geurts 1997 provides other arguments in favor of the definite description hypothesis, which we will examine shortly. However, it can be (and has been) objected that proper names in argument positions do not generally behave as straightforward definite descriptions in that they exhibit the well-known property of rigidity of reference (Kripke 1980), to which we now turn.

\subsection{Indexicality of argument proper names}

It is well-known that noun phrases, and in particular definite descriptions, in argument positions can be read de re (73a) or de dicto (73b):

(73) Mary considers the man to be a fool.

a. $\Rightarrow$ The unique (contextually relevant) male individual in $\mathrm{w}_{0}$ is a fool in Mary's belief-worlds

b. $\Rightarrow$ The unique (contextually relevant) male individual in Mary's belief-worlds is a fool in Mary's belief-worlds

The prevalent view in semantic and philosophical theories of proper names, starting from Kripke (1980) is that this property doesn't hold for proper names in argument positions, as shown by (74) forming a minimal pair with (73):

(74) Mary considers Peter to be a fool.

a. $\Rightarrow$ The individual called Peter in $\mathrm{w}_{0}$ is a fool in Mary's belief-worlds

b. $\nRightarrow$ The individual called Peter in Mary's belief-worlds (who might be John in $\mathrm{w}_{0}$ ) is a fool in Mary's belief-worlds 
Whereas a definite description can be interpreted either de re or de dicto, a proper name is only interpreted de re. In other words, a proper name always denotes the same individual in all possible worlds - proper names refer rigidly. ${ }^{15}$

A possible account for the rigidity of proper names comes from the widespread proposal that it results from indexicality, since indexicals such as $I$, now or here are also known to denote the same individual across different possible worlds. To arrive at this compositionally, one has to assume that proper names contain an indexical-and the question is, which indexical?

One proposal (Burge 1973) is that the meaning of proper names contains a demonstrative and the occurrence of Alice in an argument position should in fact be interpreted as that Alice. Larson and Segal (1995) implement this proposal by assuming that the null demonstrative that is present in syntax. Of several arguments against this view presented by Elbourne (2002), the most basic one comes once again from languages with an overt definite article with proper names: why is there no overt demonstrative?

A pragmatic view, due to Lerner and Zimmermann $(1984,1991)$ and Haas-Spohn (1995), makes reference to the usage that is salient in the context. A variation of this view (Recanati 1997; Pelczar and Rainsbury 1998) makes use of the indexical of the name-assigning convention or dubbing in force. As is clear from the sample lexical entry in (58), repeated below, this latter hypothesis is the one I would like to use.

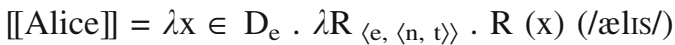

where $\mathrm{n}$ is a sort of the type e (a phonological string)

In order to account for the rigidity of proper names in argument positions I propose to compare proper name predicates with relational nouns like friend and adjectives like local and close, which may take a contextually supplied indexical as an argument.

a. Lucy went to a local bar.

b. She is a good friend.

$=$ local to Lucy, or local to HERE $=$ my friend

Both local and friend require an internal argument that is not overt in examples (75). One possible analysis (Mitchell 1986, Partee 1989; Martí 2003) is to assume that this slot can be saturated by a covert free variable receiving its value from the context. Extending this analysis to proper names, we hypothesize that in argument positions the naming convention argument slot is saturated by a free variable-that of the naming convention in force between the speaker and the hearer, or more strictly speaking, the naming convention of the speaker that is presupposed to be shared by the hearer. This convention (I will indicate it as $\mathrm{R}_{0}$ ) is indexical in the sense of being fully extensional: it contains no argument slot for a possible world. As a result, proper names in argument positions will be rigid.

\footnotetext{
15 Geurts (1997) argues that the generalization is in fact untrue and provides several counter-examples to it. An alternative way of dealing with Geurts' exceptions, which relies once again on the naming convention argument slot, will be discussed in Sect. 4.3.
} 
(76) [the Alice $]=1 x \cdot R_{0}(x)$ (/ælis/), where $R_{0}$ is the naming convention in force between the speaker and the hearer

One argument first levied against definite description theories of proper names by Kripke (1980) relies on the fact that substitution of a proper name such as Alice for the corresponding definite description the individual named Alice does not yield the same truth-conditions: (77a) (with named understood as a resultant state) is a logical truth with existential import, whereas $(77 \mathrm{~b})$ is not:

(77) a. The individual named Alice is named Alice. a logical truth: F (1x. F(x))

b. Alice is named Alice. not a logical truth

Our treatment of the problem is the same as Geurts'. Under our proposal, the interpretation of (77b) is roughly equivalent to (77c):

c. The unique individual such that the naming convention in force between the speaker and the hearer $\mathrm{R}_{0}$ holds between this individual and the phonological string /ælıs/ is named Alice.

The naming convention in force between the speaker and the hearer is not necessarily the same as the naming convention established by the verb name (on which more below) and so the subjects in (77a) and (77b) need not denote the same individual, which is why the substitution fails. ${ }^{16}$

The issue of rigidity is the second one (after that of proper names in naming constructions) where the hypothesis advocated here (58) and the one proposed by Geurts (1997) (56) diverge. As can be easily seen from the exposition above, both (56) and (58), being fully extensional, predict the rigidity of proper names. However, whereas I intend to maintain the extensionality of proper names, Geurts argues that they should, in fact, be treated as intensional in order to account for a number of cases where proper names behave non-rigidly, to which we now turn.

\subsection{Non-rigid uses of argument proper names}

If proper names are rigid, their reference cannot vary with context. Nonetheless, argument proper names, just like definite common xNPs, can function as bound variables (Geurts 1997) and as E-type expressions (Elbourne 2002): ${ }^{17}$

\footnotetext{
16 A question that arises immediately in this context is that of why proper names are extentional, whereas other nouns (common nouns) are not. I tentatively propose that this hypothesis is less ad hoc than it seems: proper names are themselves decomposed into the lexical part (the phonological string corresponding to the name) and the functional part, introducing the naming relation. It is this functional part that it extensional, thus rendering proper names less unusual as lexical items. Further motivation for a decompositional analysis of proper names is provided in Sect. 7.4.

17 While discussing how the referential/attributive distinction (Donnellan 1966) applies to proper names, Kripke (1980) introduces an example where two people mistakenly identify Smith as Jones and talk about him while using the name Jones to refer to him. I contend that this is not an attributive use of a proper name, since in the given context it is completely rigid and determined by the naming convention in use between these people. See also Bach (1981) for a discussion.
} 
(78) a. If a child is christened 'Bambi', then Disney will sue Bambi's parents.

b. Every woman who has a husband called John and a lover called Gerontius takes only Gerontius to the Rare Names Convention.

It is obvious that Bambi in the consequent of the conditional in (78a) and Gerontius in the matrix of (78b) refer to different individuals in different possible worlds, thus violating Kripke's generalization. ${ }^{18}$

How do we deal with these examples, given that lexical entry in (58) is fully extensional, i.e. does not leave any room for a possible world? I propose to make use of the hypothesis that the $\mathrm{R}$ argument slot of a proper name is saturated by a contextually provided free variable, or in other words, a functional pronoun of the semantic type $\langle e,\langle n, t\rangle\rangle$.

One striking fact about the cases where proper names in argument positions exceptionally behave non-rigidly is that in all these cases the concept of naming is explicitly introduced in the preceding context. In Sect. 5 I will argue that a naming verb introduces an existential quantifier over naming conventions. In other words, the meaning of (79a) is something like (79b):

(79) a. The child is christened Bamby.

b. [I [vP $\bigvee_{\text {name }}[\mathrm{sC}$ the child Bamby]] ] $\approx \lambda \mathrm{w} . \exists \mathrm{R}[\mathrm{R}$ is a christening convention in $\mathrm{w} \& \mathrm{R}$ ([[the child]])(/bæmbi/)

In other words, the use of a naming verb introduces existential quantification over naming conventions just like the use of an indefinite article introduces existential quantification over entities. As is well-known, a pronoun appearing outside the syntactic scope of an indefinite NP can nevertheless appear to be bound by it (the so-called "donkey" sentences):

(80) a. A man walked in. Something happened to him.

b. If a man walked in now, something would happen to him.

c. Every time a man walks in, something happens to him.

The contextually provided variable that can saturate the naming convention argument slot is a pronoun. Whereas the default naming convention in force between the speaker and the hearer is available in the absence of an antecedent, like a first person pronoun, other naming convention variables can only be used if they are made explicit in the preceding context (or, potentially, by deixis), like third person pronouns.

\footnotetext{
${ }^{18}$ It could be argued that examples (78) are rather awkward. As Geurts (1997) points out, this awkwardness is an epiphenomenon due to a general constraint against repetition and resurfaces in parallel examples (i) involving definite descriptions. Geurts (1997) shows that such examples can be improved by introducing a competing antecedent as a reason for repetition, as in (ii):

(i) a. If a man is elected president, the president will be male. b. Mary talked to no senator before that senator was impeached.

(ii) a. If you call your children Bamby and Thumper, Thumper is not likely to thank you. b. If a man is elected president and a woman, vice-president, only the president will be male.
} 
In other words, the pronoun saturating the naming convention argument slot for the second use of proper names in (78) is anaphoric to the naming convention introduced by the existential quantifier in the naming verb. Whatever analysis is chosen to account for exceptional scope cases in (80), it can be extended to (78), as in all these examples the naming verb introduces existential quantification over naming conventions.

Importantly, the violation of rigidity of reference in examples like (78) is due not to the presence of a possible world argument slot in proper names, but in the variation in naming conventions introduced by the naming verb, even though the naming convention itself remains in no way intensional.

One more comment is in order. Examples like (78) are highly marked. While the approach advocated here permits us to account for them, it also sheds some light on their relative infelicity. The existential quantifier over naming conventions that makes it possible to interpret argument proper names non-rigidly is part of the lexical entry for the naming root. As a result the entity that it "introduces" cannot be easily referred to, and the resulting sentences are odd.

A more complicated issue is that of the possible narrow scope of proper names, illustrated in the following example from Bach (1987):

(81) The electoral process is under attack, and it is proposed, in light of recent results, that alphabetical order would be a better method of selection than the present one. Someone supposes that 'Aaron Aardvark' might be the winning name and says, 'If that procedure had been instituted, Ronald Reagan would still be doing TV commercials, and

[(12)] Aaron Aardvark might have been president.'

There are multiple problems with this example. First of all, it seems to me that in this case Aaron Aardvark refers rigidly to the person so named in the actual world. Some support for this intuition comes from the fact that the proper name Ronald Reagan in the first conjunct of the relevant clause appears to do so. Furthermore, since the semantics of counterfactuals takes into consideration only the possible worlds closest to ours, there is no reason to assume that naming conventions in the worlds differing only in the election procedure would be different from ours.

Secondly, in order to obtain the desired reading with the desired surface syntax, it is necessary that the election procedure involve a random bijective assignment of names to individuals. In this case, the example would be amenable to the same treatment as (78). Even so I must admit that I do not find it fully grammatical and feel that an Aaron Aardvark would have been required.

Geurts (1997) also introduces the following examples, where the proper names in the subject position seem to be indefinite, despite the absence of the article:

(82) a. In English, Leslie may be a man or a woman.

b. But John is always male. 
In this use of Leslie and John to mean 'an individual named Leslie or John', the proper names seem to scope under the modal. However, this example involves a covert conditional (in English) that appears to make reference to something very similar to a naming convention (a language), which suggests that it can also be treated like (78).

The final remaining question has to do with the interpretation of examples like (83).

(83) If some people call Alice "Al”, Freddy is not happy.

Let's assume that we have two individuals, a (Alice) and f (Alfred). While $a$ is generally referred to as Alice, $f$ is usually called Al. However, there are a few people, who, because they use "Al" to refer to $a$, call $f$ "Freddy" (and he doesn't like this). (83) cannot be used to describe this situation - in other words, the naming convention introduced as a result of the existential in the naming root (call) in the antecedent of the conditional in (83) cannot be used in calculating the referent of the argument proper name Freddy in the consequent. Why is it so?

My explanation is tentative and once again has to do with the treatment of counterfactuals. I propose that by default naming conventions introduced by naming verbs are viewed as identical to the naming convention in force between the speaker and the hearer except for the relations explicitly mentioned. In other words, though call introduces a naming convention in (83), the naming construction doesn't explicitly mention $f$ (Alfred) and therefore the naming convention introduced by it is assumed to differ from the default naming convention in force between the speaker and the hearer only in what concerns the relation between /æl/ and a (Alice).

\subsection{Complex and modified proper names}

Treating proper names as unanalyzable entities makes it difficult or impossible to address the syntax and semantics of complex proper names (Miss Alice Liddell) and modified proper names (the young Frankenstein). Our semantics makes the task relatively simple.

\subsubsection{Complex proper names}

An additional argument in favor of a predication-based analysis of proper names can be drawn from complex and plural proper names:

a. Sherlock Holmes

b. Annie and Ron Smith

The interpretation of complex proper names seems to be fully intersective (but see Sect. 4.4.3 for a discussion of some complications). The interpretation of conjoined proper names can be obtained in whatever way the interpretation of conjoined NPs is, though I leave the details of composition aside here (see e.g., Heycock and Zamparelli 2003): 


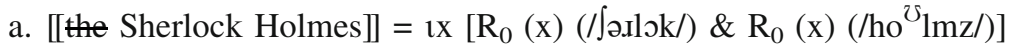
where $R_{0}$ is the naming convention in force between the speaker and the hearer

b. [the Annie and Ron Smith] $=\imath \mathrm{X} \exists \mathrm{x}_{1}, \mathrm{x}_{2}=\leq_{\mathrm{i}} \mathrm{X}\left[\mathrm{R}_{0}\left(\mathrm{x}_{1}\right)(/ \mathfrak{m n i} /)\right.$ $\left.\& \mathrm{R}_{0}\left(\mathrm{x}_{1}\right)(/ \mathrm{smi} \theta /) \& \mathrm{R}_{0}\left(\mathrm{x}_{2}\right)(/ \mathrm{s} \mathrm{s} /) \& \mathrm{R}_{0}\left(\mathrm{x}_{2}\right)(/ \operatorname{smi} \theta /)\right]$ where $\mathrm{R}_{0}$ is the naming convention in force between the speaker and the hearer

One gratifying result of this approach is that it allows us to easily derive the entailment that Sherlock Holmes is Sherlock and that he is Holmes. Another is that the treatment of coordinated proper names can be assimilated to the treatment of coordinated common nouns (though many issues, including the behavior of plurality here, remain):

(86) a. the remaining squares and circles

b. the black and white squares

Furthermore, under the assumption that proper names become one-place predicates once the argument slot of the naming convention has been taken care of, they can combine with other predicates in the same way nouns do:

a [the Miss Alice Liddell] $=1 x$ [miss $(x) \& R_{0}(x)(/ æ l ı s /) \& R_{0}(x)($ LIol $\left.)\right]$ where $R_{0}$ is the naming convention in force between the speaker and the hearer

b. [the famous detective Sherlock Holmes] $=1 \mathrm{x}[$ famous(x) \& $\operatorname{detective}(\mathrm{x})$

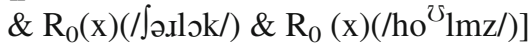
where $\mathrm{R}_{0}$ is the naming convention in force between the speaker and the hearer

Plural proper names such as the Clintons and perhaps certain morphologically transparent diminutives (e.g., Ninocka 'Nina-DIM-DIM-NOM.SG' in Russian or Rosita 'Rosa-DIM' in Spanish) can also be analyzed as compositional.

\subsubsection{Restrictive modification}

Examples like (87b) are intriguing in more than the fact that they contain two proper names in juxtaposition. Proper names in such examples resemble common nouns in that they are modified, and the modification can be restrictive (88a) or non-restrictive $(88 \mathrm{~b}):^{19}$
a. the older Miss Challoner
b. the charitable Miss Murray

there are two people named Miss Challoner there's only one Miss Murray (Anne Brontë, Agnes Grey, p. 165)

\footnotetext{
19 On the obligatory use of the article with such modification in French and some other languages, as well as on the role of the chosen adjective, see Matushansky (2006b). 
Our approach, where proper names in argument positions are treated exactly in the same way as DPs based on common nouns, predicts the availability of modification. Nothing special needs to be said about the semantics of modified proper names, with one possible exception:

(89) The Paris of the forties was not a nice place to be.

At first blush, temporal modification in (89) (Kayne 1994; Gärtner 2004) is something that names do and definite descriptions seem not to do, and the similarity between proper names and common nouns seems to break down (90a). However, once we draw a parallel with kinds (cf. Kripke 1980), we see that common nouns interpreted as kinds do permit temporal modification along the same lines (90b):

(90) a. *The house of the forties housed Bill's aunt and her extended family.

b. The human of that era was not yet fully bipedal.

If the interpretation of (90a) involves stages of a kind-individual (cf. Carlson 1977), while the interpretation of (89) is obtained by reference to stages of an object, then in both cases, all we need to compositionally obtain the required interpretation is predicate modification, though this still does not explain why (90b) is ungrammatical. I tentatively suggest that the availability of temporal modification is linked to the possibility of generic interpretation, though I can offer no explanation for this connection.

Further discussion of modified proper names in English and French can be found in Sloat (1969), Kleiber (1981), Gary-Prieur (1991, 1994, 2001), Jonasson (1994), Kayne (1994), Paul (1994), Gärtner (2004), Borer (2005) and Matushansky (2006b).

\subsubsection{The mode of combination}

As observed by an anonymous reviewer, if the intersective interpretation of complex proper names results from Predicate Modification, we cannot deal with the essential ordering difference between first and last names, predicting instead that Sherlock Holmes and Holmes Sherlock have the same meaning. This is obviously incorrect, which means that a simple juxtaposition of the two proper names, however it is obtained syntactically, cannot be correct.

A related problem arises from the fact that noun-noun (or rather, $\mathrm{xNP}-\mathrm{xNP}$ ) combinations are not normally allowed, except in compounding:
a. a woman teacher
b. * a tall woman English teacher

compounding

$\mathrm{xNP}-\mathrm{xNP}$ combination

The two issues are obviously related: how does a first name combine with a last name in syntax so that the result is asymmetrical? I will not provide a full answer to this question, but I will attempt to sketch a possible direction for future research into it.

It seems relatively straightforward to conclude that the compounding analysis cannot be applied to complex proper names. First of all, they do not fit into the interpretational pattern of compounds, where the first noun is perceived as a kind of 
a modifier on the second one (instead, it would seem that the surname is viewed as a modifier on the first name). Secondly, their stress pattern is not that of compounds and thirdly, complex proper names exist in languages (e.g., Russian) that do not have productive noun-noun compounding. ${ }^{20}$

However, combinations involving a proper name and another DP are possible in English, as illustrated below:

a. my sister the economist

b. Chomsky the philosopher
$=$ my sister(,) who is an economist $=$ Chomsky in his guise as a philosopher

The structures in (92), whatever they might be, differ in their interpretation from what we would have expected for complex proper names. The first NP in the construction exemplified in (92a) must be relational (sister, neighbor, etc.) and a possessive is obligatory. On the other hand, in the construction exemplified in (92b) the second NP has to be interpreted as contrastive and bears focal stress (e.g., Chomsky the philosopher as opposed to Chomsky the linguist). ${ }^{21}$ Moreover, the modification in (92b) is not necessarily on the level of individuals (distinguishing between two different individuals named Chomsky), but can also be on the level of guises. Neither of the two properties holds with complex proper names.

Conversely, however, the construction in (92b) also involves a proper name as its first component and the interpretation of last names is in fact restrictive, which suggests that complex proper names might, in fact, have the same underlying structure. Nonetheless, this still leaves us with the task of determining what this underlying structure might be. Although I will not attempt to do it here, the first hypothesis to examine would be that the second DP in (92) is a nominal reduced relative, comparable to the adjectival reduced relatives (93a) or (93b), which are also known to be constrained, both syntactically and semantically (cf. Bolinger 1967; Kayne 1994): ${ }^{22}$

\footnotetext{
${ }^{20}$ Even though native Russian surnames are morphologically adjectives, this is not true for surnames borrowed from other languages, nor for patronymics, which decline as nouns rather than adjectives.

${ }^{21}$ I have been able to find a non-contrastive use of this construction, but it seems rather marked:
}

(i) All cleverness, whether in the rapid use of that difficult instrument the tongue, or in some other art unfamiliar to villagers, was in itself suspicious... (George Eliot, Silas Marner)

22 An interesting support for treating complex proper names as involving modification comes from Persian, where complex proper names (i) behave like modified common nouns (ii), in that the first name is marked with the ezafe vowel (Kahnemuyipour 2000). As (iii) shows, the ezafe vowel does not indicate that the constituent that bears it is a modifier-rather, the ezafe vowel appears on the linearly first constituent in modification structures, whatever its semantic role is:

(i) Arsalan-e Kahnemuyipour

Arsalan-EZ Kahnemuyipour

(ii) sag-e qahveyi-ye gonde dog-EZ brown-EZ big a big brown dog

(iii) kif-e charm

bag-Ez leather leather bag 
(93) a. stars visible

b. work done

As mentioned above, the interpretation of complex proper names is directly relevant to the issue of their underlying structure. Although reduced relatives are interpreted intersectively, the status of the head NP is not the same as that of the predicate. The difference in the interpretation of the linearly first name in (94) might follow if the reduced relative structure is assumed:
a. Ashley Brooks
b. Brooks Ashley

For a variety of reasons, among which the length of this already very long paper, I will not treat this issue here and limit myself to a few more observations concerning the asymmetry of first, last, middle and other names.

The first thing to note is that the set of first names and the set of last names are generally distinct, English being an exception rather than the rule. Nonetheless some intersection between the two can be observed in many languages and an ordering constraint is generally present. This suggests once again that first and last names should be given different treatment. ${ }^{23}$

Another issue is the correct treatment of patronymics, nicknames and similar phenomena:
a. Mikhail-ovich (Michael's son's patronymic)
Russian patronymics
b. Mikhail-ovna (Michael's daughter's patronymic)

a. Katil-ius (a man's last name)

Latvian surnames

b. Katil-iene (a married woman's last name)

c. Katil-iute (an unmarried woman's last name)

Red, Shorty, Pumpkin...

The existence of morphologically derived proper names (patronymics, nicknames and even first names in some cultures), whose internal structure remains semantically transparent, creates a problem for the hypothesis that predicate proper names contain an unanalyzable phonological strong as a sub-component of their meaning. This complicated issue is also left for future research.

\subsection{The behavior of the definite article}

The proposal that argument proper names are definite descriptions raises the question of why it is only in some languages and with some names that this article becomes overt. Why is the definite article absent in such proper names as Alice?

\footnotetext{
23 Interestingly, in Japanese, where relative clauses precede rather than follow their head NPs, the last name also precedes the first name in conventional usage. This fact provides further support for the parallel with reduced relatives. Unfortunately, I do not believe that the pattern is general.
} 
I believe that the ability to "absorb" the definite article is a purely morphological property of a particular lexical item, and is essentially the same property as the ability to appear with a special preproprial article in languages like Catalan or Northern Norwegian. Some support for this view comes from the fact that modification interferes with this ability: thus modified proper names in English nearly always appear with articles (see Sloat 1969; Gallmann 1997; Borer 2005; Matushansky 2006b for discussion):

(98) a. the *(French) Mary Poppins

restrictive

b. the *(young) Mozart

c. the *(incomparable) Callas

non-restrictive

Although Longobardi (1994, 1999 et seq.) treats (99a) as involving N-to-D raising over the modifying adjective, this analysis cannot possibly be extended to (99b), where the modifier is nominal, or to (99c), where two articles are present:
a. Brueghel the Younger
b. Jack the Ripper
c. the young Richard the Lion-Hearted

Evidence for the similarity between article drop and the ability to appear with a dedicated preproprial definite article in Catalan comes from the fact that in modification contexts instead of the special article en/na the regular el/la article is used (Coromina i Pou 2001; Maria Núria Martí Girbau, p.c.):

(100) el Pau que vam conèixer a la festa
the Pau that go-1PL meet at the party
the Paul that we met at the party

In Matushansky (2006b) I suggest that the absence of the article with definite proper names is a morpho-syntactic phenomenon and utilize the mechanism of m-merger (Matushansky 2006a) to account for it. For space reasons I can neither spell out this proposal here, nor compare it to the view taken by Longobardi (1994, 1999).

\subsection{Coercion of proper names with determiners}

Besides examples where indefinite proper names are understood as "entity named X", there are other cases, where proper names appear with overt articles in languages that normally use them without. One such case is what Boër (1975) and Gary-Prieur (1991, 1994) call the metaphoric use of the proper name, where the phonological sequence corresponding to the proper name is no longer interpreted as proper in any way:

(101) He is such a (typical) Jeremiah - very Old Testament, very protestant, very proper.

The difference between (62) and (101) is that (101) presupposes that there are properties that all people called Jeremiah share (i.e., there's a kind referred to as 
Jeremiah). The more exotic examples in (102) may or may not be instances of the same phenomenon:

(102) a. She is a veritable Mary Poppins.

b. St. Peterburg was considered the Venice of the North.

This is a case of coercion, where the proper name NP acquires the meaning, roughly, 'an individual having the typical properties associated with the unique individual that is called Mary Poppins/Venice'. In other words, the proper name here seems to have become common: a new kind is created, whose members share properties other than just having the same name. The set of relevant properties is determined by the properties of the single individual bearing that name (in popular perception).

A completely different kind of coercion is illustrated in (103), where the derived common noun refers to the product or produce of the entity bearing the proper name (see De Clercq 2008 for some discussion).

(103) a. The museum acquired a Rembrandt and a Corot last year.

b. How's the last Agatha Christie?

c. It is easy to choose between a Beaujolais and a St. Emilion.

d. Mathias Rust flew a Cessna.

I am not ready to discuss either the intricacies of such conversions or the differences and similarities between them at this point, but they distinctly show that even with an overt article the distinction between proper names and common nouns still persists: while for the former, individuals in their extension share one property (that of bearing a particular name), for latter exactly the opposite is true: various instances of a kind (a common noun) necessarily share some properties other than the word used to refer to them. A proper name can turn into a common noun as a result of one of several coercion processes, but crucially, all these uses are constructed around the referential use of a proper name that functions as the input to coercion.

\subsection{Summary}

We have examined the use of proper names in argument positions and shown that the complex lexical entry proposed in (58) can account for them along the same lines as the simpler lexical entry in (56) proposed by Geurts (1997). Immediate benefits arising from treating argument proper names as definite descriptions consisting of a proper name predicate and a determiner include the straightforward explanation for the preproprial definite article in languages where proper names must be introduced by a determiner, a preliminary intersective analysis of complex and modified proper names and an indexical treatment of the rigidity of proper names arising from the nature of the naming convention used by default. An advantage of my analysis is that it allows for a straightforward way of dealing with bound and E-type uses of proper names discovered by Geurts (1997) and Elbourne (2002). 


\section{Proper names in predicate positions}

Given the sample lexical entry in (58), how do we compositionally obtain the meaning in (104)?

(104) [Alice is nicknamed $\mathrm{Al}]^{\mathrm{w}} \approx \exists \mathrm{R}[\mathrm{R}$ is a nicknaming convention in $\mathrm{w} \&$ $\mathrm{R}$ (Alice)(/æl/) in w]

Two points about (104) require immediate clarification. First of all, the lexical entry that we have proposed for a proper name is not intensional, while naming constructions definitely invoke non-rigid relations between entities and proper names. Secondly, the use of the existential quantification over nicknaming conventions in (104) must be justified.

We begin with the natural assumption that the naming small clause is combined with the naming verb directly and that the meaning of a proper name predicate is as in (58), repeated here:

$$
\begin{aligned}
& \llbracket \text { Alice }]=\lambda \mathrm{x} \in \mathrm{D}_{\mathrm{e}} \cdot \lambda \mathrm{R}\langle\mathrm{e},\langle\mathrm{n}, \mathrm{t}\rangle\rangle \cdot \mathrm{R}(\mathrm{x})(/ \mathfrak{x} \text { Is } /) \\
& \text { where } \mathrm{n} \text { is a sort of the type e (a phonological string) }
\end{aligned}
$$

\subsection{Event decomposition}

I adopt a decompositional approach to the event semantics of verbs cast in the framework of Distributed Morphology, where the change-of-state component of the meaning and its causative component are introduced by functional $\mathrm{v}^{0}$ heads known as BECOME and CAUSE with the usual semantics associated with these heads (see Dowty 1979, Hale and Keyser 1993; von Stechow 1995, 1996; Levin and Rappaport Hovav 1995; Rappaport Hovav and Levin 1998; Harley 2003).

This means that naming verbs project the complex structure in (105), where the CAUSE component of the naming vP assigns the theta-role of the AGENT of baptizing:

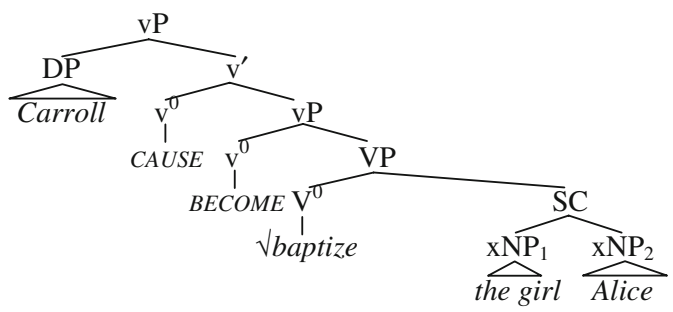

The presence of the aspectual BECOME component is confirmed by case-marking on $\mathrm{xNP}_{2}$ in the Finnish examples (32) and (33), repeated below. ${ }^{24}$ (32) shows that in

\footnotetext{
${ }^{24}$ Strictly speaking, case-marking only functions as evidence for a particular functional head assigning it in the standard Case Theory, where cases are assigned (or checked) by heads. In the non-standard theory proposed by Matushansky (2008) the BECOME component need not be projected in syntax, but may be a feature on some functional or lexical head, encoding the associated presupposition or conversational implicature.
} 
small clauses with a change-of-state meaning, the predicate is marked with the translative case, presumably assigned by the BECOME $v^{0}$ (Fong 2003). (33) shows that in naming constructions $\mathrm{xNP}_{2}$ is also marked translative.

a. Me valits-i-mme Sue-n presidenti-ksi.

nomination we elect-PST-1PL Sue-ACC president-TRS

We elected Sue president.

b. Me maalas-i-mme seinä-n keltaise-ksi.

resultative

we paint-PST-1PL wall-ACC yellow-TRS

We painted a/the wall yellow.

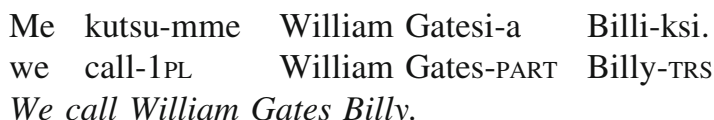

naming

We call William Gates Billy.

Another argument, due to Danny Fox, p.c., in favor of having more than one event in the structure associated with verbs of naming is modification by again. As shown by von Stechow $(1995,1996)$ and Beck and Johnson (2004), with a changeof-state verb, again can modify either of the events involved: ${ }^{25}$

(106) Ali Baba opened Sesame again.

a. Ali Baba restored Sesame to the state of being open

restitutive

b. Ali Baba repeated the action of opening Sesame.

repetitive

Von Stechow $(1995,1996)$ argues that the restitutive reading of (106), paraphrased in (106a), results from again scoping below the CAUSE $\mathrm{v}^{0}$, while in its repetitive reading, paraphrased in (106b), again scopes higher than the CAUSE $v^{0}$. Exactly the same argument can be offered for verbs of naming:

You can't call her Griselda again.

In its repetitive reading (107) can be used in a situation where the challenge is to give a doll different names without ever repeating oneself. The restitutive reading of (107) suits the situation where the task is not to repeat the name (i.e. not to cause the doll to have the same name). We therefore see that naming verbs have as complex an event structure as change-of-state verbs, with the final state described by the combination of the verbal root with the small clause. In the interests of transparency I will treat this final state as if it denoted a proposition becoming true at the time provided by the BECOME component, though in reality it should probably be treated as a stative eventuality. Thus, in what follows I will be completely abstracting away from the agent of the naming verb and the time and event argument of the naming small clause, if any.

\footnotetext{
${ }^{25}$ Both this and the next example face the same problem: the causing event cannot be readily distinguished from the transition to the final state (Was Sesame made open again or did it become open again? Is the вEсоме component of the meaning merely an implicature?). We will not address the issue here, as not directly relevant.
} 
5.2 The naming small clause complement

The lexical entry in (58), repeated below, means that a small clause with a proper name predicate will have the compositional semantics in (108).

[[Alice] $=\lambda \mathrm{x} \in \mathrm{D}_{\mathrm{e}} \cdot \lambda \mathrm{R}_{\langle\mathrm{e},\langle\mathrm{n}, \mathrm{t}\rangle\rangle} \cdot \mathrm{R}(\mathrm{x})\left(/ \Re \mathrm{lis}_{\mathrm{s}}\right)$

where $\mathrm{n}$ is a sort of the type e (a phonological string)

(108) $\llbracket$ the girl Alice $\rrbracket=$

$=\llbracket$ Alice $]([$ the girl $\rrbracket)=$

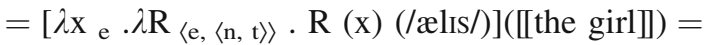

$=\lambda \mathrm{R} . \mathrm{R}\left([\right.$ the girl] $)\left(/ æ \mathrm{IIS}_{\mathrm{s}}\right)$

where $\mathrm{n}$ is a sort of the type e (a phonological string)

In other words, the small clause complement of a naming verb still has one open argument slot-that of the naming convention. I propose that it is saturated by the embedding naming verb.

\subsection{The naming verb}

In order to provide a compositional account of how proper name predicates are interpreted in naming constructions, I adopt a Distributed Morphology approach, where verbs are decomposed both syntactically and semantically. Importantly, the conclusions drawn in the previous sections do not depend on the success or failure of this analysis-it is here to provide a possible way of treating the empirical phenomena discussed above.

Separating the agent and the event from the root of the naming verb, I propose that the root in (105) introduces an existential quantifier over naming conventions, while restricting them to a certain subclass (determined by the lexical content of the naming root). In addition, dependence on the world and time of evaluation must be taken into consideration: unlike argument proper names, predicate proper names are not rigid.

Suppose that a naming root, for instance, baptize, invokes a particular function (BAPTISM) that evaluates whether a given relation of the semantic type $\langle e,\langle n, t\rangle\rangle$ is a baptismal convention in the possible world w. ${ }^{26}$ It then must be checked if there exists such a relation between the subject of the small clause and the phonological string quoted in the contents of the proper name that is the predicate of that small clause. Then the meaning of the VP in (105) is something like (109)—note that the agent of the baptizing event and the event argument are yet to be introduced:

(109) $\llbracket\left[\mathrm{vvP}_{\mathrm{V}}{ }_{\text {baptize }}[\mathrm{sC}\right.$ the girl Alice $\left.\left.]\right]\right]=\lambda \mathrm{w} . \exists \mathrm{R}\langle\mathrm{e},\langle\mathrm{n}, \mathrm{t}\rangle\rangle[\mathrm{BAPTISM}\langle\langle\mathrm{s},\langle\mathrm{e},\langle\mathrm{n}, \mathrm{t}\rangle\rangle\rangle, \mathrm{t}\rangle$ $(\mathrm{w})(\mathrm{R}) \& \mathrm{R}([$ the girl]])(/ælıs/)

where $\mathrm{n}$ is the sort of phonological strings

\footnotetext{
${ }^{26}$ I set aside for the moment the question of whether naming is also evaluated with respect to time intervals in order to simplify the exposition.
} 
In other words, the VP denotes a proposition that is true in the possible world $\mathrm{w}$ iff there exists a relation between the girl and /ælıs/ such that this relation is a baptism convention in $\mathrm{w}$.

Naming verbs therefore resemble possibility modals: while the latter introduce restricted existential quantification over possible worlds, the former restrict and existentially quantify over naming conventions. The reason to assume that naming verbs introduce existential quantification (rather than an iota operator or a universal) is the fact that one naming convention involving the subject of the naming small clause does not exclude the existence of others:

(110) Her parents have called her Elisabeth, but everyone calls her Libby now.

Likewise, the behavior of naming predicates under negation also favors the presence of an existential quantifier (Daniel Büring, p.c.):

(111) Not named Elvis or Prince, Kurt Zipfel had to find himself an appropriate stage persona.

(111) means that Kurt Zipfel is not named Elvis or Prince under any naming convention, with the existential quantifier in the lexical entry of the verb necessarily scoping under negation.

To obtain (109) compositionally, no additional assumptions are required. Since a proper name has two argument slots, of which the first one is of type $e$, the combination of a proper name with its subject is completely straightforward, as in (108). If the root of a naming verb has the lexical entry as in (112), the composition is direct:

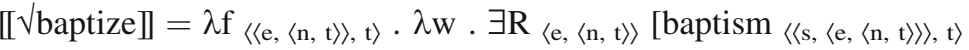

$$
\begin{aligned}
& (\mathrm{w})(\mathrm{R}) \& \mathrm{f}(\mathrm{R})]
\end{aligned}
$$

In other words, the root of a naming verb takes its small clause complement as an argument and introduces restricted existential quantification over naming conventions, while relativizing them to possible worlds.

As mentioned earlier, in order to combine this VP with the BECOME component (if present) and the CAUSE component, its semantics must be slightly modified in accordance with the chosen theory of change-of-state verbs (cf. Dowty 1979; Kratzer 1994, von Stechow 1995, 1996) in order to incorporate an eventuality argument (a state) and possibly a temporal argument as well. I will not attempt to do this here.

\subsection{Non-naming predication}

We now return to proper names with ECM and raising verbs, as well as in secondary predication, where no naming verb is available. Two issues should be addressed with respect to these: why is such predicative use possible at all and why does it feel marked? 
Geurts' lexical entry in (56) predicts that a proper name small clause should not be able to combine with any verb. Since a proper name predicate only has one argument slot, that for the subject, once this position is saturated, the small clause has the semantic type $t$. At first blush, this seems correct: examples (113), while grammatical, don't have the desired interpretation where the proper name would be interpreted as a predicate meaning 'named $\mathrm{X}$ '.

(113) a. \#The happy parents made their daughter Alice.

b. \#She was Beth Clark.

The lexical entry in (58), with its argument slot for a naming convention, yields the same result: once the $\mathrm{R}$ argument slot of the proper name is saturated by the contextually available free variable of the naming convention in force between the speaker and the hearer, introduced in section 4 , the proper name small clause should be unable to combine with anything:

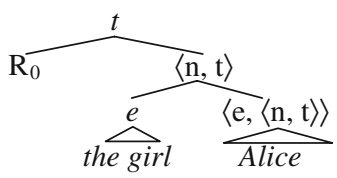

If the naming convention argument slot is not saturated, the resulting small clause has the semantic type $\langle\mathrm{n}, \mathrm{t}\rangle$, which is also incompatible with any verb but a naming one.

However, this result seems partially incorrect, given the availability of examples like (49), repeated below, and (115). Although such examples feel marked in the sense that the meaning of "being named so-and-so" is made very prominent, they are nonetheless interpretable: ${ }^{27}$

(49) Born [PRO Charles Lutwidge Dodgson], the man who would become

Lewis Carroll was an eccentric and an eclectic.

(115) Once she went to school, she stopped being Esmeralda and became simply Es.

At this point it could be assumed that Geurts' lexical entry in (56) and my lexical entry in (58) must contain one more argument slot that would permit a naming small clause to combine with something else in order to derive (49) and (115). The problem is that by both Geurts' and my analyses, (49) and (115) would still be predicted to be completely uninformative, since the naming convention in question,

27 Many examples of this kind involve a name change after marriage:

(i) a. Her first marriage made her Mrs. Narcisse Pensoneau.

b. After her second marriage she became Mrs. John Dawson.

However, these examples also have an irrelevant reading, where Mrs. is interpreted as "the wife of", which is why I set them aside in this discussion. 
be it introduced explicitly or implicitly, is presupposed to be shared by the speaker and the hearer. ${ }^{28}$

I hypothesize that this is in fact true and explains not only why such examples are marked, but also why they make very prominent the meaning of "being named soand-so". I propose that the discourse function of such examples is to make explicit the relativization of $\mathrm{R}_{0}$ to particular times or places:

(65) She was Lo, plain Lo, in the morning, standing four feet ten in one sock.

She was Lola in slacks. She was Dolly at school. She was Dolores on the dotted line. But in my arms she was always Lolita (Vladimir Nabokov, Lolita).

(116) Dr. Asher is Claire in France and Klara in Germany.

In other words, I suggest that no new naming conventions are implied in the interpretation of (49), (65), (115) and (116). Instead the speaker emphasizes the fact that $\mathrm{R}_{0}$, the naming convention in force between the speaker and the hearer, is in fact relativized to specific places and times. It is this relativization that makes it possible for naming small clauses to appear as complements to change-of-state verbs, despite the fact that neither the naming convention $\mathrm{R}_{0}$ nor the proper name predicate normally have a temporal argument slot.

Due to the tentative nature of the proposal, I will not attempt to express it in formal terms. Other ways of dealing with the same issue, one of them introducing a covert equivalent of the verbal root call, can be imagined, although introduction of null elements has the disadvantage of undermining the intuition that the proper name in these environments is a predicate.

\section{Conclusion and topics for future research}

I have used cross-linguistic evidence to argue that proper names can enter syntax as predicates when they appear in the naming construction. Evidence for the predicate status of proper names in the naming construction comes from their case-marking (which cross-linguistically appears to be systematically the same as that of predicates), disappearance of definite articles in languages where proper names appear with a definite article in argument positions and the appearance of copulas and copular particles in naming constructions.

If proper names can be predicates, argument proper names can be viewed as definite descriptions, which explains why in some languages and with some proper names the definite article is obligatory. In Sect. 3 I proposed a novel analysis of proper names as underlyingly two-place predicates with an argument for the naming

\footnotetext{
${ }^{28}$ In addition, the predicative use of proper names so derived is predicted to be extensional, i.e., Sue's beliefs in (i) should be about the state of affairs in all possible worlds.
}

(i) Sue believes that after her second marriage she became Mrs. John Dawson.

I will not even attempt to evaluate the validity of this result. 
convention, which I motivated in Sects. 4 and 5. As a result, proper names in argument positions are treated as definite descriptions utilizing the indexical of the naming convention in force between the speaker and the hearer and naming verbs are viewed as introducing an existential quantifier over naming conventions, in exactly the same way as attitude verbs introduce a universal quantifier over possible worlds.

No part of this analysis is in itself surprising. The proposal that proper names in argument positions are definite descriptions quoting the phonological form of the name itself dates back at least as far as Kneale (1962) and has been recently advocated by Geurts (1997). The idea that their rigidity is due to a hidden indexical has also been discussed, as noted above. My contribution as I see it is to provide independent evidence from naming verbs for a definite description analysis with a "quotation" predicate and a hidden indexical of the naming convention in force between the speaker and the hearer, and derive the necessary meanings compositionally.

The interpretation of argument proper names is compositionally obtained in the following way: if proper names can enter syntax as predicates (as argued in Sect. 2), then in argument positions (unless some other determiner is present) they are definite descriptions. As a result, argument proper names are compatible with there being more than one person with a particular name in the same way definite descriptions are compatible with there being more than one entity satisfying the restrictor of the article: as a result of covert domain restriction à la von Fintel (1994) (cf. Bach 1981, 2002). We can also deal with complex and modified proper names in the same way as with modified common nouns.

The postulated argument slot for a naming convention permits us to explain why argument proper names are rigid (Kripke 1980). In the general case, the naming convention argument slot is saturated by the indexical of the naming convention in force between the speaker and the hearer, while in exceptional cases it can be introduced by the naming verb and anaphorically referred to by a null pronoun.

Finally, we have seen that in order to compositionally obtain the correct meaning for the VP consisting of a naming verb and a small clause with a proper name predicate, no new assumptions must be made, beyond a particular form for the lexical entry of naming verbs. The argument slot for the naming convention is quantified over when the naming small clause combines with a naming verb. Naming verbs are therefore viewed as existential quantifiers over naming conventions, parallel to the interpretation of attitude verbs as universal quantifiers over possible worlds.

The most important feature of the analysis is that this definite description theory of proper names is independently motivated in all its components. Cross-linguistic syntax of the naming construction shows that proper names can be predicates, and that in the naming construction they must be analyzed as predicates. Its compositional semantics makes it imperative that the meaning of a proper name make use of a naming convention, and the nature of this convention be supplied-either by the verb, or by the context. This new argument slot becomes essential when we turn to proper names in argument positions, because it allows us to provide an natural source for the rigidity/indexicality of proper names. 
It should be noted that the lexical entry for proper names that I have proposed obviously sheds no light whatsoever on how proper names happen to refer to those individuals that they refer to, or in other words, how the connection between a particular phonological string and a particular individual is established. This issue is shifted to the pragmatics of naming conventions and becomes akin to lexical semantic issues like what it means to be a doctor.

Furthermore, we are still far from having solved all the problems posed by proper names. Some of the remaining issues (e.g., the absence of the definite article with definite proper names in languages such as English) are morphosyntactic, others (e.g., default and non-default proper names, discussed by Saul (1997) and Zimmermann (2005), or the interpretation of predicate proper name in the absence of a naming verb) are semantic, and yet others (e.g., the fact that in certain environments, such as Dutch possessives, proper names behave as if they were heads) are syntactic. I leave the discussion of these issues for future work in the hope that the approach advocated here will help resolve at least some of them.

\section{Appendix: Alternative structures for the naming construction}

In Sect. 2 I argued that cross-linguistically, the naming construction involves a small clause. In this section I will discuss various alternative proposals: (a) a ditransitive structure, (b) resultative or depictive secondary predication, and (c) control.

\section{Double object}

For languages with overt copulas in small clauses, like Korean (Sect. 2.5), or overt predicate case-marking (Sect. 2.6), it is well-near impossible to argue that $\mathrm{xNP}_{2}$ may not be a predicate. This is why we constrain our discussion of double object analyses to languages where no overt morphology or preproprial definite articles (Sec. 2.4) can give us a clue as to whether $\mathrm{xNP}_{2}$ is referential.

$x N P_{1}$ is not the GOAL, $x N P_{2}$ is not the THEME

At a first glance, the naming construction seems to involve ditransitive syntax, with $\mathrm{xNP}_{1}$ serving as the GOAL of the action and $\mathrm{xNP}_{2}$ as its THEME. The naming construction would then involve two objects:

(117) a. give one's daughter a name

b. name one's daughter Alice

To exclude this analysis in English it is enough to consider the passivization properties of naming verbs. It is a general property of English that to passivize, an argument has to start out as the object of a verb (or of a preposition, in pseudopassives). GOAL and THEME can both do so:

(118) a. Marie was given a book.

GOAL

b. A book was given to Marie.

THEME 
However, in naming constructions only $\mathrm{xNP}_{1}$ can passivize: ${ }^{29}$

(119) a. Caesar was nominated/elected/declared consul (by the Senate).

b. *A/the/Ø consul was nominated/elected/declared Caesar (by the Senate).

(120) a. I was called/christened/named/baptized Al.

b. *Al was called/named/baptized me.

This means that $\mathrm{xNP}_{2}$ does not behave like the THEME object in English, and therefore, the naming construction cannot involve two objects. A similar argument can be constructed for Dutch, where in double object constructions, only the most internal argument (the accusative one, though it is not case-marked) can be passivized (Eddy Ruys, p.c..):
a. het Marie/ ? een meisje gegeven boek the Marie/ a girl given book the book given to Marielto a girl
b. *het Anna Karenina/een boek gegeven meisje the Anna Karenina/a book given girl

If verbs of naming had ditransitive syntax, we would have expected the THEME to be able to passivize, and the GOAL to be unable to do so. In other words, the proper name should behave like $a$ book and the name-bearer should behave like $a$ girl. The facts are exactly the opposite:

$$
\begin{aligned}
& \text { a. de Marie genoemde/gedoopte vrouw } \\
& \text { the Marie named/baptized } \\
& \text { the woman named/baptized Marie } \\
& \text { b. *de een vrouw genoemde/gedoopte } \\
& \text { the a Marie } \\
&
\end{aligned}
$$

naming

The putative GOAL in the Dutch naming construction can be "externalized"/ passivized, while the putative THEME cannot. This is unsurprising if the naming verb is not a ditransitive, but takes a small clause complement, and the behavior of the nomination construction supports this conclusion:

$$
\begin{aligned}
& \text { a. ?de de baas gemaakte vrouw } \\
& \text { the the boss made } \\
& \text { the woman made the boss } \\
& \text { b. **de een vrouw gemaakte baas } \\
& \text { the a woman made } \\
&
\end{aligned}
$$

small clause

? under the reading the boss made into a woman

\footnotetext{
29 One could argue that passivization failure in (120) is due to the non-referentiality of the proper name, since it is equally impossible to passivize the direct object in idioms like give someone a break, give someone a start, etc. One possible objection to that is that the naming construction is not idiomatic and semantically fully transparent; another-that in ditransitive analyses of naming verbs, the proper name is intended to denote an entity-namely, its own phonological form.
} 
It is easy to see that $\mathrm{xNP}_{1}$ doesn't behave like the GOAL object in Dutch, either. The same kind of argumentation can be attempted for any language with suspected ditransitive syntax.

$x N P_{1}$ movement

In modern English, genuine ditransitives (dative or applicative) do not allow Heavy NP Shift, unless a dative preposition is inserted:

(124) a. They gave the office *(to) the most talented candidate they could lay their hands on.

b. Hadrian built a city *(for) the young man he loved most dearly.

Verbs of naming behave like ECM and nomination verbs in grudgingly allowing right-dislocation of $\mathrm{xNP}_{1}$ if $\mathrm{xNP}_{1}$ is very heavy and/or contrastive (Heavy NP Shift):

(125) She will consider stupid *Harriet/?? only the most obvious idiot in the whole country.

(126) a. The Senate nominated/elected/declared consul *Caesar/? the most talented candidate they could lay their hands on.

b. Call/name/christen/baptize $\mathrm{Al} *$ me/ ${ }^{?}$ the first man you will meet on this journey.

\section{The lexical category of the predicate}

A major difference between ECM and ditransitive verbs is that ECM verbs allow non-nominal predicates, while ditransitives only permit nominal objects. Verbs of naming seem to behave more like ditransitives than like ECM here, since as a rule, $\mathrm{xNP}_{2}$ cannot be replaced by an $\mathrm{AP}$ or a PP:

(127) a. Alice gave Beth a book/the book/*interesting/*in the room.

b. Name/christen/baptize me *French/*talented/*charming/*in the room.

However, verbs of naming share this inability to take a non-nominal predicate with some verbs of nomination:
a. *The Senate nominated/elected him great/amazing.
b. Amy was declared innocent/amazing.

The only naming verb allowing adjectival predicates is call, but as we have already noted, call is too often exceptional and appears in constructions other than naming.

The inability of naming verbs to take non-nominal predicates is not conclusive, since we know that ECM verbs can constrain the lexical category of the predicate in their complement (Stowell 1981): 
(129) a. I consider Elizabeth clever/a friend/in the running/*(to) live in Paris.

b. I let Elizabeth *clever/*a friend/into the house/(*to) live in Paris.

c. I made Elizabeth clever/a professor/*into the house/(*to) live in Paris.

d. I allowed Elizabeth *clever/*a friend/*into the house/*(to) live in Paris.

Another possible explanation comes from the fact that the semantics of naming verbs is such that they must combine with proper names. As is easy to see, whatever their surface form is, proper names are nouns, most likely as a result of their semantics:
a. Red, Black
b. Shorty, Golden

simplex adjectival names derived adjectival names

This means that the restriction may not be on the naming verbs but on names -naming verbs do not constrain the lexical category of the predicate, but lexical items with the meaning of a proper name happen to be always nominal. The decompositional approach sketched in this paper provides for an easy way of accounting for this phenomenon.

\section{Alternation classes}

Another possible argument against analyzing naming verbs as ditransitives is the fact that ditransitives usually allow some sort of an alternation in the argument ordering, effected via a preposition:

(131) a. give Coraline the key $\rightarrow$ give the key to Coraline dative alternation

b. bake Mommy a cake $\rightarrow$ bake a cake for Mommy applicative alternation

No similar PP-alternate exists for verbs of naming, just like there is no such alternation with ECM verbs and verbs of nomination: ${ }^{30}$

(132) a. dub the knight Sir Lancelot $\rightarrow *$ dub Sir Lancelot for/to/... the knight

b. declare Arthur king $\rightarrow *$ declare king for/to/... Arthur

c. make/consider Arthur great $\rightarrow *$ make/consider great for/to/... Arthur

As usual, a null preposition analysis is impossible to rule out.

\section{Conclusion}

There's nothing a priori wrong with the double object hypothesis, and this is consistent with the fact that some languages employ this strategy. It just seems unlikely for the languages considered.

\footnotetext{
${ }^{30}$ Interestingly, some nomination verbs have a transitive variant where the $\mathrm{xNP}_{2}$ predicate turns into the direct object (David Pesetsky, p.c.):
}

(i) declare the winner, elect the president

The object must be definite, which makes the construction resemble certain semantic incorporation cases such as play the piano. I have nothing to say about this phenomenon. 


\section{Control}

The control structure is potentially compatible with the syntactic data discussed above: it would still allow the proper name in the naming construction to be predicative (and marked as such), but it would avoid the necessity of treating naming verbs as ECM verbs. The structure in (133) can be interpreted as "Carroll named his heroine, and his heroine became Alice", which in a sense is just the resultative construction:

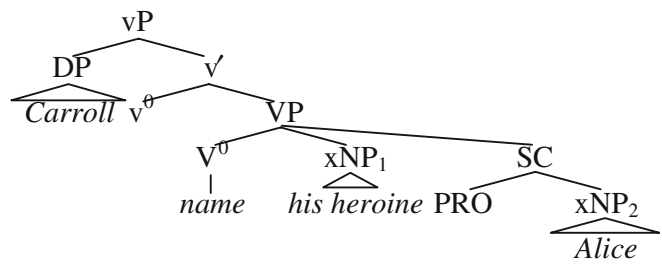

Two objections can be raised against the control hypothesis. The first one is that unmistakable control verbs, such as persuade or promise, never take small clause complements and do take xVP complements. ${ }^{31}$ Exactly the opposite is true of naming verbs, as discussed in Sect. 2.7: verbs of naming can combine with naming small clauses only.

The second objection is that the semantics of the naming construction does not fall into the range of control verb semantics. As Comrie (1984) observes, there is a clear semantic difference between subject and object control verbs, and between two types of subject control verbs:

- Subject control verbs, type 1: have the meaning of "mental orientation", expectation or desire. Examples include want, wish, hope, need, hate and expect.

- Subject control verbs, type 2: verbs of "commitment", including try, promise, decide, agree, refuse and threaten.

- All the object control verbs are verbs of "influence" (convince).

Verbs of naming do not belong to any of these classes and do not necessitate a [- human] object:

\section{(134) Tolstoy named his book "Anna Karenina”.}

However, there exists another environment projecting the control structure with a small clause: that of secondary predication.

\section{Secondary predication}

Secondary predicates (depictives or resultatives) also often feature case agreement. Can it be that verbs of naming and nomination do involve small clauses, but not as primary predication?

\footnotetext{
31 Iatridou (1990), Matushansky (2002a): the epistemic version of sound and other perception verbs might involve control. See Miller (2003) for the counter-argument.
} 
The first major argument against this view is the fact that secondary predicates are always optional. Though with certain verbs, such as the exceptional verb call or baptize, the predicate can be omitted (and the meaning changes drastically), other naming verbs do not allow predicate omission:
a. Will you call your daughter, please?
b. Every Christian is baptized.
c. *Every gangster is nicknamed.

A priori, the secondary predicate analysis fares better than the primary predicate analysis because it can deal with examples like (135a, b). However, we can easily see that this hypothetical secondary predicate behaves neither like a depictive nor like a resultative.

\section{Finnish: against depictives}

A straightforward example of a recognized depictive is (136):

(136) Alice returned to her hometown [sC PRO rich/a president/in a good mood].

The first argument against analyzing verbs of naming as involving a depictive secondary predicate is the simple fact that its interpretation is incompatible with the meaning of the depictive: the small clause predication in depictives describes the state of affairs that obtains at the culmination of the event denoted by the main verb, while with verbs of naming and nomination, the small clause describes the result of the naming/nomination.

As mentioned above, the distinction between these two interpretations is reflected by case-marking in Finnish: Finnish depictive DPs bear essive case, as opposed to $\mathrm{xNP}_{2}$ in the naming construction, which is marked translative. Translative also appears with verbs of nomination and in resultatives (exx. due to Liina Pylkkänen, p.c.):

$$
\begin{aligned}
& \text { Alice palas-i kotikaupunki-in-sa } \\
& \text { Alice return-past hometown-illative-3sG.POSS } \\
& \text { rikkaa-na/presidentti-na. } \\
& \text { rich-ESs/president-ESS } \\
& \text { Alice returned to her hometown rich/a president. }
\end{aligned}
$$

a. Me nimi-t-i-mme William Gates-in presidentti-ksi. nomination we name-PST-CAUS-1PL William Gates-ACC president-TRS We named William Gates president.

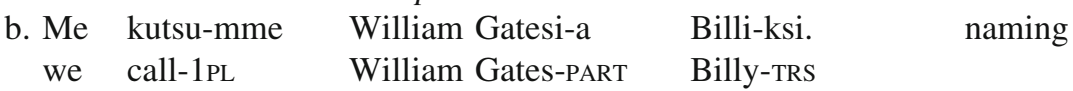
We call William Gates Billy.

c. Me maalas-i-mme seinä-n keltaise-ksi. resultative we paint-PST-1PL wall-ACC yellow-TRS We painted a/the wall yellow. 
We conclude that the depictive analysis is inapplicable in Finnish, which means that at least for this language we need an alternative explanation, involving a small clause. This brings us to the next question-can verbs of naming and nomination be resultative?

\section{Russian: against resultatives}

The same kind of an argument can be used in this section-for at least some languages in our sample, the resultative proposal cannot work, and thus a different hypothesis is necessary. Since we already have such a hypothesis, the resultative analysis, even if it works for some languages, is unnecessary.

One reason for rejecting the resultative analysis comes from the fact that no language that I know of allows nominal resultatives without a preposition:

We hammered the metal flat/*sword/*a sword/ $\checkmark$ into a sword.

The fact that Russian does not allow nominal or adjectival resultatives provides a further argument against the resultative approach to the naming construction.

\section{Benefactives and incorporation}

Although we have only discussed languages where naming constructions involve small clauses, many languages use the ditransitive structure to convey the same meaning, as in the example (140) from Georgian (Lea Nash, p.c.):

$$
\begin{array}{llll}
\text { man } & \text { kališvils } & \text { meri } & \text { jaarkua. } \\
\text { he-ERG } & \text { daughter-DAT } & \text { Mary-NOM } & \text { name-3-AoR } \\
\text { He named his daughter } & \text { Mary. }
\end{array}
$$

This means that in some languages proper names can be treated as direct objects and have one of the possible argument types $e$ or $\langle\langle\mathrm{e}, \mathrm{t}\rangle, \mathrm{t}\rangle$. The most natural meaning for a proper name in such a language would be the actual quotation, i.e., the phonology of the name ("mention", as opposed to "use"). We then expect substitution of the proper name by an expression like "the name N" to be possible.

Interesting questions arise. If proper names can have the "mention" meaning as well as the naming predicate meaning, can one be derived from the other? We have discussed and dismissed (Sect. 3.1) the possibility of incorporating the predicative component of predicate proper names into the main verb, but could the meaning of predicate proper names itself be composed, not just in the lexical entry, where a proper name does contain the "mention" of itself, but compositionally, in syntax and semantics?

I believe that the fact that the meaning of a proper name contains not only the phonological string itself but also the relation that holds between this string and an individual bearing the proper name (the naming convention $\mathrm{R}$ ) makes it possible to 
treat at least some proper names as morphologically complex entities. This would also provide for a natural explanation of how any phonological string can become a proper name.

If correct, this analysis makes the following prediction: in languages, where naming verbs appear in a ditransitive structure and the proper name functions as a direct quotation, the syntax of the proper name should show similarities with quotations, for instance, lack of case-marking (or surface nominative case).

\section{Summary}

A brief examination of possible alternative structures for naming verbs shows that even where morphology does not provide unambiguous evidence for a small clause analysis, there are other factors permitting us to exclude these alternatives. Although some languages appear to use an explicitly marked double-object construction for naming verbs, we maintain that most naming verbs are best treated as taking a small-clause complement.

Acknowledgement I am very grateful to Alec Marantz, Barry Schein, Björn Rothstein, Daniel Büring, Danny Fox, David Pesetsky, Eddy Ruys, Francois Recanati, Gennaro Chierchia, Irene Heim, Jim Higginbotham, Kai von Fintel, Philippe Schlenker, Sylvain Bromberger, and Tania Ionin for the discussion and suggestions, to the many linguists who provided data on various more or less exotic languages and will be individually named (though not called or baptized) below. I would also like to thank the audiences at NELS 35, Sinn und Bedeutung 9, UCLA syntax and semantics seminar, MIT syntax-semantics reading group, and seminars of volet VP de la Fédération TUL (CNRS/Université Paris 8), Johann Wolfgang Goethe Universität Frankfurt am Main, Institut Jean Nicod, PALMYR and CRISSP for their attention and helpful comments, and, last but not the least, the three anonymous reviewers of Linguistics and Philosophy, whose detailed comments greatly improved this paper.

Open Access This article is distributed under the terms of the Creative Commons Attribution Noncommercial License which permits any noncommercial use, distribution, and reproduction in any medium, provided the original author(s) and source are credited.

\section{References}

Abbott, B. (2005). Proper names and language. In G. N. Carlson \& F. J. Pelletier (Eds.), Reference and quantification: The Partee effect (pp. 1-19). Stanford, CA: CSLI Publications.

Bach, K. (1981). What's in a name. Australasian Journal of Philosophy, 59, 371-386.

Bach, K. (1987). Thought and reference. Oxford: Oxford University Press.

Bach, K. (2002). Giorgione was so-called because of his name. Philosophical Perspectives, 16, $73-103$. Bailyn, J. (2001). The syntax of Slavic predicate Case. ZAS Papers in Linguistics, 22, 1-26.

Bailyn, J., \& Citko, B. (1999). Case and agreement in Slavic predicates. In K. Dziwirek, H. S. Coats, \& C. Vakareliyska (Eds.), Formal approaches to Slavic linguistics 7: The Seattle meeting (pp 17-37). Ann Arbor, Michigan: Michigan Slavic Publications.

Bailyn, J., \& Rubin, E. J. (1991). The unification of instrumental case assignment in Russian. In A. Toribio \& W. Harbert (Eds.), Cornell Working Papers in Linguistics 9 (pp 99-126). Ithaca, New York: Department of Modern Languages and Linguistics, Cornell University.

Barker, C. (1998). Partitives, double genitives and anti-uniqueness. Natural Language \& Linguistic Theory, 16, 679-717.

Beck, S., \& Johnson, K. (2004). Double objects again. Linguistic Inquiry, 35, 97-124.

Boër, S. E. (1975). Proper names as predicates. Philosophical Studies 27, 389-400.

Bolinger, D. (1967). Adjectives in English: Attribution and predication. Lingua, 18, 1-34.

Boone, A. (1987). Les constructions Il est linguiste/C'est un linguiste. Langue Française, 75, 94-106. 
Borer, H. (2005). Structuring Sense 1. In Name Only. Oxford: Oxford University Press.

Bowers, J. (1993). The syntax of predication. Linguistic Inquiry, 24, 591-656.

Burge, T. (1973). Reference and proper names. Journal of Philosophy, 70, 425-439.

Campbell, G. L. (1991). Compendium of the World's Languages 2. Maasai to Zuni. New York: Routledge.

Carlson, G. N. (1977). Reference to kinds in English. Doctoral dissertation, University of Massachusetts, Amherst.

Chierchia, G. (1998). Reference to kinds across languages. Natural Language Semantics, 6, 339-405.

Cho, S. (1998). A new analysis of Korean inalienable possession constructions. In Proceedings of the North East Linguistics Society, 28, 79-93.

Chomsky, N. (2001). Derivation by phase. In M. Kenstowicz (Ed.), Ken Hale: A life in language (pp 1-52). Cambridge, Mass.: MIT Press.

Comrie, B. S. (1984). Subject and object control: Syntax, semantics and pragmatics. In Proceedings of the Tenth Annual Meeting of the Berkeley Linguistics Society. Berkeley, CA: Berkeley Linguistics Society.

Coromina i Pou, E. (2001). L'article personal en català. Marca d'oralitat en l'escriptura. Doctoral dissertation, Universitat Autònoma de Barcelona.

De Clercq, K. (2008) Proper names used as common nouns in Belgian Dutch and German. Ms., CRISSP/ University College Brussels. Available at http://ling.auf.net/lingBuzz/000628.

de Swart, H., Winter, Y., \& Zwarts, J. (2005). The interpretation of bare predicate nominals in Dutch. In E. Maier, C. Bary, \& J. Huitink (Eds.), Proceedings of SuB 9 (pp. 446-460). Nijmegen: NCS.

Delsing, L.-O. (1993). The internal structure of noun phrases in the Scandinavian languages. Doctoral dissertation, University of Lund.

Donnellan, K. S. (1966). Reference and definite descriptions. The Philosophical Review, 75, $281-304$.

Dowty, D. R. (1979). Word meaning and Montague grammar. Dordrecht: Reidel.

Elbourne, P. (2002). Situations and individuals, Doctoral dissertation, MIT.

Fong, V. (2003). Resultatives and depictives in Finnish. In D. Nelson \& S. Manninen (Eds.), Generative approaches to Finnic and Saami linguistics. Stanford: CSLI.

Frampton, J., \& Gutmann, S. (2000). Agreement is feature sharing. Ms., Northeastern University.

Frege, G. (1983). On sense and reference. In P. Geach \& M. Black (Eds.), Translations from the Philosophical Writings of Gottlöb Frege. Oxford: Blackwell (1952).

Gallmann, P. (1997). Zur Morphosyntax der Eigennamen im Deutschen. In E. Löbel \& G. Rauh (Eds.), Lexikalische Kategorien und Merkmale. Linguistische Arbeiten 366, 72-84. Tübingen: Niemeyer.

Gärtner, H.-M. (2004). Naming and economy. In O. Bonami \& P. C. Hofherr (Eds.), Empirical issues in formal syntax and semantics 5. Available at http://www.cssp.cnrs.fr/eiss5.

Gary-Prieur, M.-N. (1991). La modalisation du nom propre. Langue Française, 92, 49-62.

Gary-Prieur, M.-N. (1994). Grammaire du nom propre. Paris: Le Seuil.

Gary-Prieur, M.-N. (2001). L'individu pluriel: Les noms propres et le nombre. Paris: CNRS Editions.

Geurts, B. (1997). Good news about the description theory of names. Journal of Semantics, 14, 319-348.

Haas-Spohn, U. (1995). Versteckte Indexikalität und subjektive Bedeutung. Doctoral dissertation, Berlin.

Hale, K., \& Keyser, S. J. (1993). On argument structure and the lexical expression of syntactic relations. In K. Hale \& S. J. Keyser (Eds.), The view from Building 20: Essays in linguistics in honor of Sylvain Bromberger. Cambridge, Mass.: MIT Press.

Harley, H. (2003). How do verbs get their names? Denominal verbs, manner incorporation, and the ontology of verb roots in English. Ms., University of Arizona.

Heim, I., \& Kratzer, A. (1998). Semantics in generative grammar. Oxford: Blackwell.

Heycock, C., \& Zamparelli, R. (2003). Friends and colleagues: Plurality, coordination, and the structure of DP. Ms., University of Edinburgh/Università di Bergamo. Available at http://semanticsarchive.net/ Archive/mRhN2FlN/fc-heycock-zamparelli03.pdf.

Iatridou, S. (1990). About Agr(P). Linguistic Inquiry, 21, 551-577.

Jackendoff, R. (1977). X-bar syntax: A study of phrase structure. Cambridge, MA.: MIT Press.

Jonasson, K. (1994). Le nom propre, constructions et interprétations. Louvain: Duculot.

Kahnemuyipour, A. (2000). Persian ezafe construction revisited: Evidence for modifier phrase. In J. T. Jensen \& G. van Herk (Eds.), Proceedings of the 2000 Annual Conference of the Canadian Linguistic Association. Cahiers Linguistiques d'Ottawa, pp. 173-185.

Katz, J. J. (1977). A proper theory of names. Philosophical Studies, 31, 1-80.

Katz, J. J. (1990). Has the description theory of names been refuted? In G. Boolos (Ed.), Meaning and method: Essays in Honor of Hilary Putnam. Cambridge: Cambridge University Press.

Katz, J. J. (1994). Names without bearers. The Philosophical Review, 103, 1-39.

Kayne, R. S. (1994). The antisymmetry of syntax. Cambridge, MA.: MIT Press.

Kleiber, G. (1981). Problèmes de référence: descriptions définies et noms propres. Paris: Klincksieck. 
Kneale, W. (1962). Modality de dicto and de re. In E. Nagel, P. Suppes, \& A. Tarski (Eds.), Logic, Methodology and Philosophy of Science. Proceedings of the 1960 International Congress (pp. 622-633). Stanford: Stanford University Press.

Kratzer, A. (1994). The event argument and the semantics of verbs. Cambridge, Mass.: MIT Press.

Kripke, S. (1980). Naming and necessity. Oxford: Blackwell.

Kupferman, L. (1979). Les constructions Il est un médecin/C'est un médecin: essai de solution. Cahiers linguistiques, 9, 131-164.

Larson, R. K., \& Segal, G. (1995). Knowledge of meaning. Cambridge, MA.: Bradford Books/MIT Press.

Lerner, J.-Y., \& Zimmermann, T. E. (1984). Bedeutung und Inhalt von Eigennamen. Papier Nr. 94 des SFB 99. Konstanz.

Lerner, J.-Y., \& Zimmermann, T. E. (1991). Eigennamen. In A. von Stechow \& D. Wunderlich (Eds.), Semantik: ein internationales Handbuch der zeitgenössischen Forschung, Papier Nr. 94 des SFB 99 (349-370). Berlin/New York: Walter de Gruyter.

Levin, B. (1993). English verb classes and alternations: A preliminary investigation. Chicago: The University of Chicago Press.

Levin, B., \& Hovav, M. R. (1995). Unaccusativity: At the syntax-lexical semantics interface. Linguistic Inquiry Monograph 26. Cambridge, Mass.: MIT Press.

Liu, J. (2004). From Kripke's puzzle to a new description theory of proper names. Ms., SUNY Geneseo.

Longobardi, G. (1994). Reference and proper names. Linguistic Inquiry, 25, 609-665.

Longobardi, G. (1999). Some reflections on proper names. Ms., University of Trieste.

Maling, J., \& Sprouse, R. A. (1995). Structural case, specifier-head relations, and the case of predicate NPs. In H. Haider, S. Olsen, \& S. Vikner (Eds.), Studies in comparative germanic syntax (pp. 167-186). Dordrecht: Kluwer.

Martí, L. (2003). Contextual variables. Doctoral dissertation, University of Connecticut.

Massam, D. (1985). Case theory and the projection principle. Doctoral dissertation, MIT. Cambridge, MA.: MIT, Department of Linguistics and Philosophy, MITWPL.

Matushansky, O. (2002a). Movement of degree/degree of movement. Doctoral dissertation, MIT. Cambridge, MA.: MIT, Department of Linguistics and Philosophy, MITWPL.

Matushansky, O. (2002b). Tipping the scales: The syntax of scalarity in the complement of seem. Syntax, $5,219-276$.

Matushansky, O. (2006a). Head-movement in linguistic theory. Linguistic Inquiry, 37, 69-109.

Matushansky, O. (2006b). Why Rose is the Rose. In O. Bonami \& P. C. Hofherr (Eds.), Empirical issues in formal syntax and semantics 6 (pp. 285-308).

Matushansky, O. (2008). A case study of predication. In F. Marušič \& R. Žaucer (Eds.), Studies in formal slavic linguistics. Contributions from formal description of slavic languages 6.5 (pp. 213-239). Frankfurt am Main: Peter Lang.

Miller, P. (2003). La complémentation directe et indirecte des verbes de perception en anglais. In J. Pauchard (Eds.), Les prépositions dans la rection verbale (domaine anglais) (pp. 115-135). Reims: Presses Universitaires de Reims.

Mitchell, J. (1986). The formal semantics of point of view. Doctoral dissertation, University of Massachusetts at Amherst.

Partee, B. H. (1986). Noun phrase interpretation and type-shifting principles. In J. Groenendijk, D. de Jongh \& M. Stokhof (Eds.), Studies in discourse representation theory and the theory of generalized quantifiers (GRASS 8, pp. 115-143). Dordrecht: Foris.

Partee, B. H. (1989). Binding implicit variables in quantified contexts. In C. R. Wiltshire, B. Music, \& R. Graczyk (Eds.), Papers from CLS 25 (pp. 342-365). Chicago: Chicago Linguistic Society.

Paul, M. (1994). Young Mozart and the joking Woody Allen. Proper names, individuals and parts. In M. Harvey \& L. Santelmann (Eds.), Proceedings of Semantics and Linguistic Theory (SALT) (Vol. 4, pp. 268-281). Ithaca, New York: CLC Publications, Department of Linguistics, Cornell University.

Pelczar, M., \& Rainsbury, J. (1998). The indexical character of names. Synthèse, 114, 293-317.

Pereltsvaig, A. (2001). On the nature of intra-clausal relations: A study of copular sentences in Russian and Italian, Doctoral dissertation, McGill.

Pollock, J.-Y. (1983). Sur quelques propriétés des phrases copulatives en français. Langue Française, 58, 89-125.

Rappaport Hovav, M., \& Levin, B. (1998). Building verb meanings. In M. Butt \& W. Geuder (Eds.), The projection of arguments: Lexical and compositional factors. CSLI Lecture Notes (Vol. 83). Stanford: CSLI.

Recanati, F. (1997). Direct reference: From language to thought. Oxford: Blackwell. 
Rouveret, A. (1994). Syntaxe du gallois: Principes généraux et typologie. Paris: CNRS Editions.

Rouveret, A. (1996). Bod in the present tense and in other tenses. In R. D. Borsley \& I. Roberts (Eds.), The syntax of the celtic languages (pp. 125-170). Cambridge: Cambridge University Press.

Roy, I. (2001). Predicate nominals in French. Ms., University of Southern California, Los Angeles.

Russell, B. (1911). Knowledge by acquaintance and by description. In B. Russell (Ed.), Mysticism and logic and other essays (pp. 209-232). London: Longmans, Green, and Co.

Saul, J. M. (1997). Substitution and simple sentences. Analysis, 57, 102-108.

Searle, J. R. (1958). Proper names. Mind, 67, 166-173.

Sloat, C. (1969). Proper nouns in English. Language, 45, 26-30.

Smith, M. (2004). A pre-group grammar for a non-configurational language. Ms., UCLA. Retrieved from http://smithma.bol.ucla.edu/qualifying-paper.pdf.

Stowell, T. A. (1981). Origins of phrase structure. Doctoral dissertation, MIT.

Stowell, T. A. (1983). Subjects across categories. The Linguistic Review, 2, 285-312.

Stowell, T. A. (1989). Subjects, specifiers and X-bar theory. In M. Baltin \& A. Kroch (Eds.), Alternative conceptions of phrase structure. New York: Academic Press.

Stowell, T. A. (1991). Determiners in NP and DP. In K. Leffel \& D. Bouchard (Eds.), Views on phrase structure (pp. 37-56). Dordrecht: Kluwer.

Strawson, P. F. (1950). On referring. Mind, 59, 320-344.

Stvan, L. S. (1998). The semantics and pragmatics of bare singular noun phrases. Doctoral dissertation, Northwestern University.

von Fintel, K. (1994). Restrictions on quantifier domains. Doctoral dissertation, University of Massachusetts, Amherst: GLSA.

von Stechow, A. (1995). Lexical decomposition in syntax. In U. Egli, P. E. Pause, C. Schwarze, A. von Stechow, \& G. Wienold (Eds.), The lexicon in the organization of language (pp. 81-118). Amsterdam: John Benjamins.

von Stechow, A. (1996). The different readings of wieder "again": A structural account. Journal of Semantics, 13, 87-138.

Williams, E. (1983). Semantic vs. syntactic categories. Linguistics and Philosophy, 6, 423-446.

Zaring, L. (1996). "Two be or not two be": Identity, predication and the Welsh copula. Linguistics and Philosophy, 19, 103-142.

Zimmermann, T. E. (2005). What's in two names? Journal of Semantics, 22, 53-96. 